\title{
MaPA e EdiPA: duas ferramentas analíticas para as relações texto-som-imagem em vídeos de música
}

\section{MaPA and EdiPA: two analytical tools for the text-sound-image relationships in music videos}

\section{Fausto Borém \\ Universidade Federal de Minas Gerais \\ faustoborem@gmail.com}

Resumo: Apresentação de duas ferramentas analíticas consecutivas, o MaPA (Mapa de Performance Audiovisual) e a EdiPA (Edição de Performance Audiovisual), com as quais proponho organizar e representar, analiticamente, conteúdos de fontes primárias constituídas por gravações de vídeo de música. O MaPA é construído a partir da seleção de fotogramas isolados ou de sequências de fotogramas extraídos do vídeo. Estas imagens são capturadas para explicitar elementos cênicos (gestos corporais, expressões faciais, objetos de cena, iluminação, efeitos de câmara, técnicas de manipulação de imagem etc.) detectados como fundamentais para a compreensão do trinômio texto-somimagem e, por isto, compreensão da expressão musical. A EdiPA é construída a partir da notação gráfica de elementos sonoros fundamentais transcritos do vídeo em algum tipo de notação musical (como na partitura tradicional, em lead sheet, em gráficos, em espectrogramas etc.) à qual são acrescentados fotogramas do MaPA com seus timings no vídeo (em minutos e segundos) e informações textuais sucintas para facilitar a compreensão das relações texto-som-imagem. A utilização de ambas as ferramentas analíticas é exemplificada com MaPAs e EdiPAs mais simples ou mais complexos. São também apresentados três tipos de gravações de vídeo (com os artistas Elis Regina e Caetano Veloso), que levam em consideração a interferência da direção artística do vídeo e níveis de liberdade ou planejamento na realização musical: (1) performance não-espontânea, (2) performance quase-espontânea e (3) performance espontânea.

Palavras-chave: análise de vídeo de música; relação texto-som-imagem; ferramentas de análise musical; interpretação de Elis Regina; composição de Caetano Veloso. 
Abstract: Introduction to two consecutive analytical tools - MaPA (Map of Audiovisual Performance) and EdiPA (Audiovisual Performance Edition), which I propose as a way to organize and represent the content of music video recordings as primary sources. MaPA stars from a selection of isolated photograms or sequence of photograms selected from the video. Its aims is to order and make scenic elements clear (body gestures, facial expressions, stage objects, lighting, camera effects, image manipulation techniques etc.). These elements are captured and considered fundamental for the comprehension of text-sound-image relationships and, thus, the comprehension of music expression. EdiPA is written to graphically represent fundamental sound elements transcribed from the video with some kind of music notation (such as a traditional score, lead sheets, graphics, spectrograms etc.) over which photograms from MaPA may be superimposed with respective timings in the video (in minutes and seconds) and succinct textual information to facilitate the comprehension of text-sound-image relationships. The tandem use of both analytical tools in here is illustrated with simple and more complex types of MaPAs and EdiPAs, and with three types of video recordings (with Brazilian artists Elis Regina and Caetano Veloso), which takes into consideration the interference of the artistic direction on the video and distinct levels of freedom in the music realization: (1) non-spontaneous performance, (2) quasi-spontaneous performance (3) spontaneous performance. Keywords: music video analysis; text-music-image relationship; music analysis tools; interpretation by Elis Regina; composition by Caetano Veloso.

\section{1 - Em torno da análise de vídeos de música}

Duas modernidades tecnológicas, a gravação e reprodução de fontes sonoras em meados do século XIX1 e a gravação e reprodução simultânea de sons e imagens em movimento no final do século $\mathrm{XIX},{ }^{2}$ mudaram nossa perspectiva

\footnotetext{
${ }^{1}$ As primeiras gravações de áudio de música foram realizadas nos dias 9, 17 e 20 de abril de 1860 pelo francês Édouard-Léon Scott de Martinville (Feaster 2010, p.60-70, 73, 81), dezessete anos antes da patente de Thomas A. Edson. Com seu phonoautograph, patenteado em 25 de março de 1857, Édouard-Léon registrou a canção folclórica francesa Au Clair de la Lune. Uma destas gravações pode ser apreciada em https://www.youtube.com/watch?v=s0fhEpxrFvo (Martinville, 1860, publicado em 2008).

2 As primeiras tentativas frutíferas de combinar música com a gravação de imagens em movimento datam de 1895, com o kinethophone de Thomas A. Edson, e 1902, com o chronophone de Léon Gaumont (Gomery 1985, p.8-9). O primeiro filme com música ao vivo, The Dickson Experimental Sound Film, realizado por William Dickson com o kinethophone entre o final de 1894 e início de 1895, mostra ele próprio tocando Song of the cabin boy (da opereta The Chimes of Normandy de Robert Planquette, 1877) e pode ser apreciado no Youtube de [0:44] a [1:01], no link https://www.youtube.com/watch?v=vfqUjBDIkT8 (Dickson, 1894-1895, publicado em 2013).
} 
de ouvir e ver a realização musical. O reforço sensorial gerado pela combinação dos estímulos sonoro e visual na reprodução automática de uma interpretação gravada potencializou a percepção da expressão artística. Na música, a audição da voz, instrumentos musicais e outras fontes sonoras, superposta à fruição de imagens do artista (com ou sem movimentos) e seu entorno, ampliou seus significados em vários níveis, como os sinais da tríade básica peirciana: ícones, índices e símbolos (Merrell 2010, p.31, 37).

As iniciativas inglesas pioneiras de utilizar gravações históricas de música como fontes primárias de pesquisas musicológicas foram coordenadas e otimizadas em duas iniciativas nacionais no início do século XXI, ambas patrocinadas pela agência de pesquisa Arts and Humanities Research Council. Primeiro, a criação do CHARM (Centre for the History and Analysis of Recorded Music) $)^{3}$ em 2004 e, depois, sua substituição pelo CMPCP (Research Centre for Musical Performance and Creative Practice) $)^{4}$ em 2009. Estas iniciativas motivaram o desenvolvimento de ferramentas analíticas para a música gravada, como softwares que lidam quantitativamente com os parâmetros andamento, dinâmica e articulação. ${ }^{5}$

Apesar da crescente produção e divulgação de resultados de análise de áudios de música, observa-se uma grande carência de trabalhos e ferramentas analíticas que abordem arquivos de vídeo de música. No final do século XX, Cook dizia que

“...a falta de habilidade generalizada dos analistas em encontrar qualquer coisa para dizer sobre a música de vídeos de música pode ter origem na falta de uma base teórica adequada para relacionar o que é ouvido ao que é visto [...] Mesmo os melhores trabalhos sobre vídeos de música [...] perdem força pela relativa crueza de suas categorias para descrever e analisar as estruturas musicais. A maioria dos pesquisadores [...] nem mesmo percebem este problema, e o resultado inevitável é que os vídeos de música acabam quase sempre analisados enquanto vídeos apenas, mas não enquanto música. Como eu disse, 'Material girl' [canção de Peter Brown e Robert Rans no álbum Like a virgin da cantora pop Madonna] parece ser o mais teorizado dos vídeos de música, mas em toda a literatura ainda não encontrei uma única sentença sequer que fale especificamente de sua música." (Cook 1998, p.150).

\footnotetext{
${ }^{3}$ O CHARM foi criado em 2004, resultado de uma parceria entre quatro instituições: University of London, Royal Holloway, King's College de Londres e University of Sheffield.

${ }^{4} \mathrm{O} C M P C P$, que substituiu o CHARM, foi criado em 2009 e resultou de uma parceria entre sete instituições: University of Cambridge, King's College de Londres, University of Oxford, Royal Holloway, University of London, Guildhall School of Music \& Drama e Royal College of Music.

${ }^{5}$ Entre os softwares de análise de música gravada criados a partir do CHARM estão Scape Plot

Generator, Data Smoother, Correlation Network Diagram Generator, Sonic Visualiser, Sonic Visualiser Session Editor, Tap Snap, Dyn-A-Matic, Keyscapes e Expression Algorithm.
} 
Hoje, quase duas décadas depois do lançamento do livro seminal Analyzing musical multimedia de Nicholas Cook (1998), ${ }^{6}$ ainda se percebe uma grande carência nesta promissora vertente de pesquisa entre a musicologia e a performance musical, interface que Goodwin (1992, p.49-71) chamou de "musicologia da imagem".

Dos 11 eventos com pesquisadores de vários países organizados pelo CHARM/AHRC e divulgados na sua página (de 2004 a 2008), apenas 2 das 159 comunicações de pesquisa tratam de análise da música gravada em vídeo (Auslander, 2015; Clayton, 2007). ${ }^{7}$ Da mesma forma, das 100 publicações do CHARM listadas em seu site

(http://www.charm.rhul.ac.uk/studies/p6_1_4.html), apenas uma parece abordar o assunto (Cook, no prelo, a partir de 2009). De fato, Nicholas Cook foi um pioneiro da análise de música gravada não apenas em áudio, mas também em vídeo. No seu livro Analysing musical multimídia, se propôs a se debruçar sobre a necessidade de "... estender os limites da teoria musical para incluir - ou pelo menos mapear - as fronteiras entre as palavras e as imagens em movimento (e também os movimentos corporais, embora eu fale pouco sobre eles [neste livro]...". Ele chama a atenção para a necessidade de "...nadar contra a enxurrada de abordagens críticas de filmes e de outras mídias narrativas que reduzem o papel da música [e, por isso, da análise de vídeos de música] a um mero apêndice, quando muito" (Cook 1998, p.vi).

Do ponto de vista da compreensão do fenômeno musical, Nicholas Cook (2013, p.251-252) vê a análise da música gravada como "a virada etnográfica" na musicologia do século XXI. Meu contato com os trabalhos do CHARM (Cook e

\footnotetext{
${ }^{6}$ Cook (1998) divide seu livro didaticamente em duas partes: a primeira, com princípios teóricos gerais e revisão de literatura e, a segunda, com estudos de caso.

${ }^{7}$ Os eventos e trabalhos sobre música gravada organizados e divulgados pelo CHARM na sua página são: o seminário Representing Performance: Musical Recordings in Culture (9 comunicações, Royal Holloway, University of London, 30 de outubro, 2004); CHARM Symposium 1: Comparative perspectives in the study of recordings (13 comunicações, Royal Holloway, University of London, 14 a 16 de April, 2005); CHARM Symposium 2: The art of record production (11 comunicações, London College of Music and Media, 17 e 18 de setembro, 2005); WestFocus seminar 1: Teaching resources for recorded music (6 comunicações, King's College of London, 1 de outubro, 2005); CHARM Symposium 3: Transfer and the recording as historical document (13 comunicações, Royal Holloway, University of London, 20 a 22 de abril, 2006); WestFocus Seminar 2: Hold that sound! Recording your amateur orchestra or choir (5 comunicações, Bertorelli Restaurant and Bar, Londres, 30 de maio, 2006); WestFocus Seminar 3: Creative production for classical music (5 comunicações, King's College of London, 5 de junho, 2006); CHARM Symposium 4: Methods for analysing recordings (18 comunicações, Royal Holloway, University of London, 12 a 14 de abril, 2007); CHARM/RMA Annual Conference: Musicology and recordings (36 comunicações, Royal Holloway, University of London, 13 a 15 de setembro, 2007); CHARM Symposium 5: Cultures of recording (19 comunicações, Royal Holloway, University of London, 10 a 12 de abril, 2008); CHARM Symposium 6: Playing with recordings (15 comunicações, Royal Holloway, University of London, 11 a 13 de setembro, 2008).
} 
Chan, 2007) reforçou a ideia de que a pesquisa em performance musical com fontes primárias audiovisuais seria minha principal trilha de pesquisa e de orientação na pós-graduação.

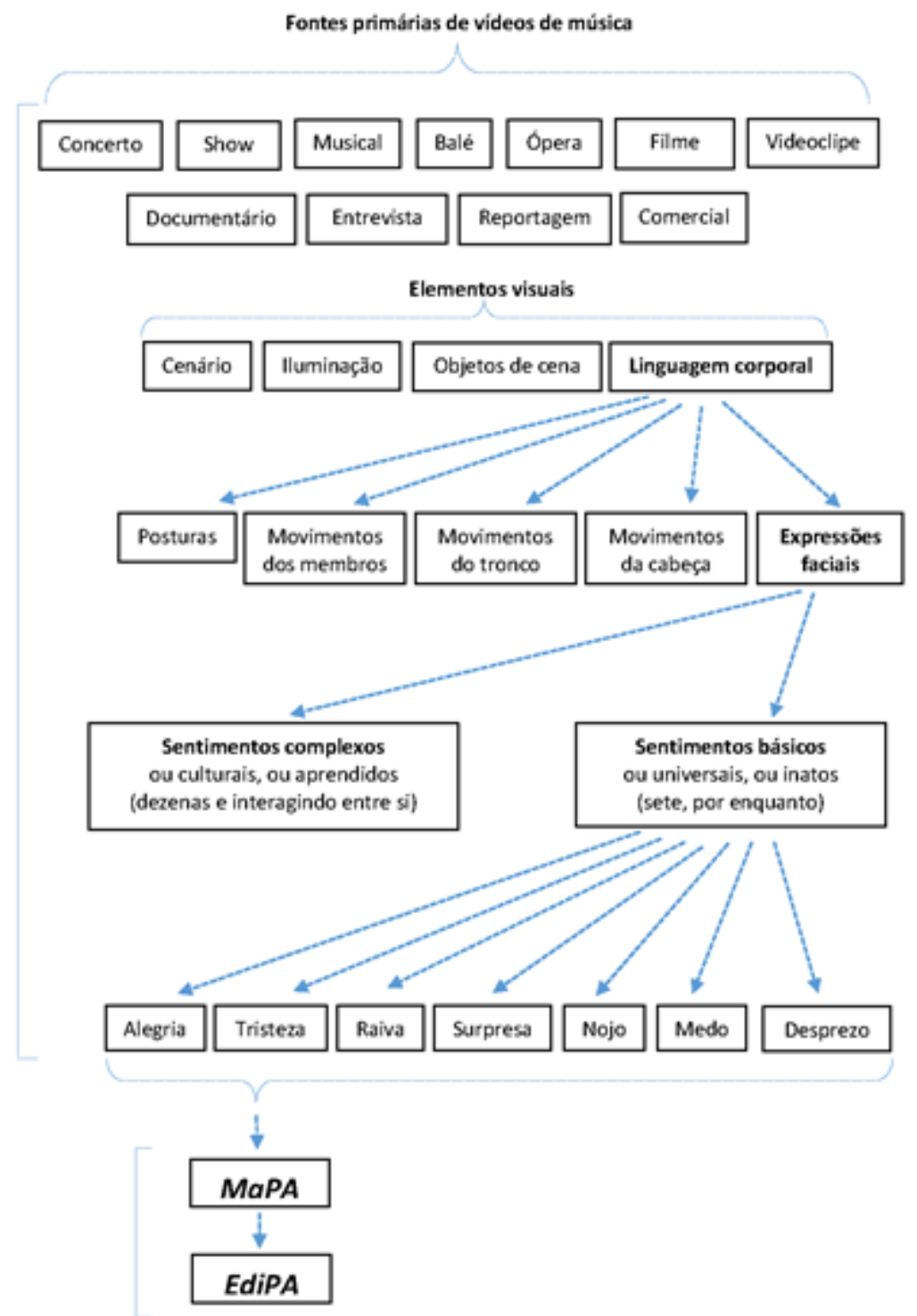

Figura 1: Organograma de fontes primárias imagéticas, delineamentos analíticos em vídeos de música e duas ferramentas - MaPA e EdiPA - propostas para síntese dos dados analíticos.

As limitações das fontes primárias constituídas de textos e partituras me levaram a buscar informações relevantes em gravações de áudio e, posteriormente, em vídeos. A análise de gravações foi essencial para que eu e meus alunos compreendêssemos melhor os estilos composicionais e de 
performance de diversos referenciais da música brasileira, ${ }^{8}$ especialmente da música popular, cuja produção é amplamente reconhecida pelo público e crítica internacionais. Para chegar ao recorte do presente artigo, procurei esboçar um organograma (Figura 1) que situasse o universo da análise de vídeo em categorias e especificidades para, ao final e no caminho inverso, permitisse reconstruir relações implícitas que não são facilmente observáveis à primeira vista e/ou audição, e cujos significados podem ser melhor explicitados ao leitor por meio das ferramentas MaPA e EdiPA.

Ainda é cedo para se falar em uma teoria abrangente para a análise de vídeos de música. No presente artigo, entretanto, ouso apresentar alguns procedimentos que culminam nestas duas ferramentas que visam sintetizar e apresentar os dados resultantes deste tipo de análise: o MaPA (Mapa de Performance Audiovisual) e a EdiPA (Edição de Performance Audiovisual). Meu caminho no desenvolvimento dessas duas ferramentas analíticas consecutivas (pois os MaPAs servem de base para as EdiPAs) se iniciou com uma motivação eclética. Minhas experiências no campo da Engenharia Civil e, depois, Arquitetura, embora incompletas, me permitiram abordar a mensuração, organização, estética e representação gráfica dos espaços físicos ocupados pelo artista durante a performance. Por outro lado, minha longa história com os esportes e colaboração interdisciplinar com o campo do Comportamento Motor (um ramo da Educação Física) me permitiu enxergar e descrever detalhes do corpo em movimento. Finalmente, minha experiência na preparação de exemplos musicais na edição de um periódico de música e em palestras contendo animações gráficas em arquivos de Power Point me deram suportes gráficos necessários para buscar uma representação mais objetiva e concisa dos eventos e suas relações sinestésicas (audição + visão) observáveis em um vídeo de música.

Como em uma boa receita gastronômica, a seleção do principal ingrediente - a fonte primária constituída pelo vídeo de música - é determinante na qualidade dos produtos finais, o MaPA e a EdiPA. Como bom e eclético cozinheiro da análise musical, Nicholas Cook (1998, p.150) sugere ser “...possível trabalhar [neste tipo de análise] a partir de conceitos teóricos musicais bem básicos para se compreender as relações da música com as palavras e as imagens...". De fato, tanto o MaPA quanto a EdiPA podem ser construídos para apontar simples interações que requerem pouco conhecimento musical.

\footnotetext{
${ }^{8}$ Os resultados de pesquisa do Grupo de Pesquisa PPP ("Pérolas" e "Pepinos" da Performance Musical) incluem publicações de análises de áudio e/ou vídeos de música de Hermeto Pascoal, Egberto Gismonti, Grupo UAKTI, Milton Nascimento, Toninho Horta, Elis Regina, Serge Koussevitsky, Francisco Mignone, Radamés Gnattali, Pixinguinha, Bonfiglio de Oliveira, Porfírio Costa, KXimbinho, Zé Bodega, Abel Ferreira, Victor Assis Brasil, Raphael Rabello, Salvador Amato e trabalhos ainda no prelo sobre Zé da Velha, Caetano Veloso, Jaques Morelenbaum e Belini Andrade.
} 
Entretanto, ao selecionar o vídeo de música, o analista deve considerar, além da qualidade (do som e da imagem na gravação) e do potencial expressivo do vídeo (significados, coesão, ineditismo e evidências da relação texto-som-imagem), suas habilidades para abordar a matéria musical (linguagens tonal, modal, atonal, serial, étnica, da música concreta, de trilha sonora etc.; estilos e práticas de performance dos gêneros populares e eruditos) e sua cultura em relação ao contexto da música (motivação composicional, aspectos programáticos, sociais etc.).

Os principais repositórios de vídeos de música são sites na internet e, por isso, recomendo que se faça o download do vídeo analisado para não se perder a fonte primária virtual. A internet também disponibiliza vídeos (profissionais e amadores) que podem revelar dados crus, os quais, transcritos, podem resultar em entrevistas inéditas e dados musicais relevantes, inexistentes na literatura impressa. Um exemplo pode ser extraído do filme Dzi Croquettes (Issa e Álvarez, 2009), no qual Luís Carlos Miéle (2009, de [03:00] a [3:25], Figura 2a), para ilustrar o espírito transgressor e improvisatório do bailarino, ator, músico e diretor Lennie Dale, narra suas alterações no final do clássico da bossa nova Você e eu de Carlos Lyra e Vinícius de Morais. No vídeo, Miéle diz que Dale substituía o “... eu sou mais você $e$ eu" da letra original por "... eu sou mais você e meu amor". Mais do que isto, Miéle narra que Dale modificava a melodia e a harmonia, sugerindo "... um tom completamente estranho..." e desafiava os bossa-novistas, dizendo “...Mas, por que ninguém fez assim, não pode? Tá errado? Vamos fazer, fica lindo!". Ainda no vídeo, Miéle canta com sotaque, imitando a versão do eclético norte-americano, o trecho transcrito e mostrado na Figura $2 b$ (Borém e Taglianetti, 2014a, p.43).
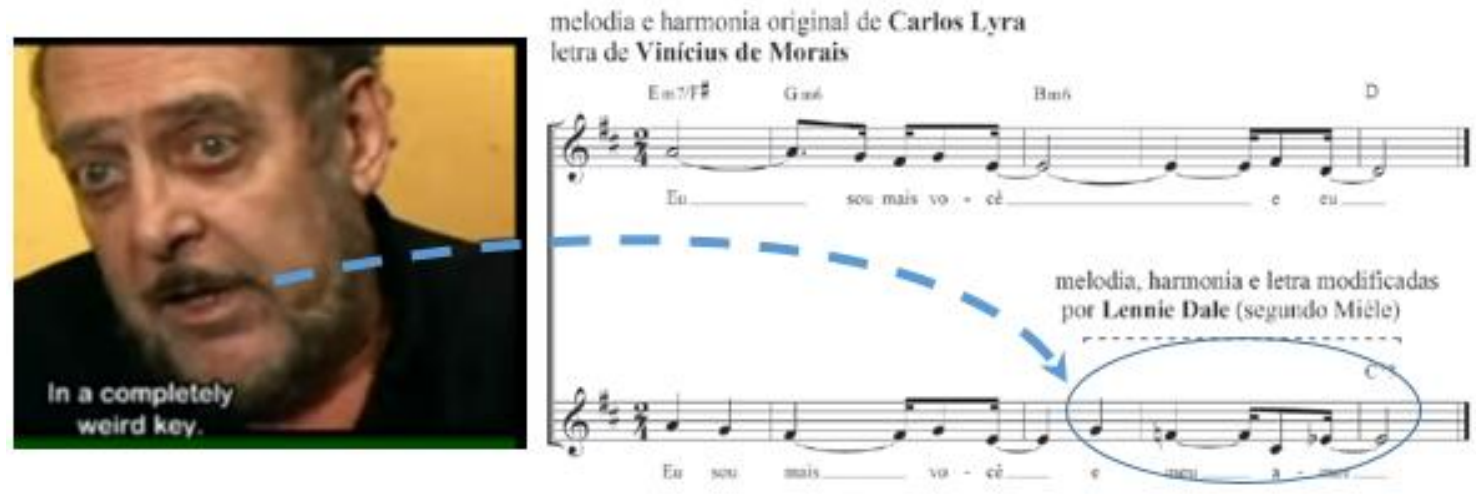

Figura 2a/2b: Transcrição da fala e do trecho cantado (letra, melodia e harmonia) na entrevista de Miéle (2009, de [03:00] a [3:25]) sobre o estilo improvisatório de Lennie Dale. 
No presente artigo são utilizados vídeos de dois artistas com longas e duradouras contribuições para a música brasileira: Elis Regina, cujas atuações emblemáticas no palco a tornaram, para muitos, um símbolo da performer completa; e Caetano Veloso, cuja produção como compositor, arranjador, letrista, cantor (em várias línguas e estilos), violonista, agitador cultural e performer o identificaram com um símbolo do músico eclético. Em relação ao planejamento na realização musical e à naturalidade da performance, exemplifico $M a P A s$ com três tipos de filmagem: (1) performance não-espontânea, em que há um roteiro minuciosamente planejado, com as ações dos intérpretes controladas, sem o esforço para que a performance seja percebida como natural, evidenciando o trabalho de corte e edição de imagens; (2) performance quase-espontânea, em que a realização musical parece natural e com pouco trabalho de edição de imagens, mas com sinais de direção de cena e coordenação de eventos e (3) performance espontânea, na qual o diretor de cena e músicos não estão presos a um roteiro ou não há um controle sobre a realização musical, que pode conter erros, emoções e eventos não planejados, em princípio impossíveis de serem repetidos.

Dentro da literatura interdisciplinar necessária para abordar as relações texto-som-imagem, destaco os campos da Biologia, Antropologia, Psicologia, Psiquiatria, Neurociências, Fisiologia, Fonoaudiologia, Linguística, Teatro e Dança. Para analisar o gestual dos intérpretes nos vídeos de música, recorro à minha adaptação para a área de música (Borém, 2014), de cinco conceitos propostos por Haga (2008) para analisar movimentos da dança, a saber: (1) Segmentação (Chunking), que divide o todo da performance em unidades autônomas menores, gestualmente bem demarcadas; (2) Contornos de Ativação (Activation Contour), que são mudanças nos níveis de atividade ou de energia que caracterizam um Segmento ou alterações de dois parâmetros do movimento, derivados da Física: Cinemática ou Dinâmica do gestual; (3) Cinemática (Kinematics), que se relaciona à trajetória e mudança de velocidade do gesto; (4) Dinâmica (Dynamics), que diz respeito às forças para iniciar ou constranger um movimento (e não o significado de intensidades tradicionalmente utilizado no campo da música); (5) Pontos de Sincronização (Sync-Points), que são pontos de sincronização relevantes entre a música e o gestual. Complementarmente, recorro a Laban (1978) para situar o corpo humano no palco, em relação às dimensões que propõe e suas gradações: Espaço, Tempo, Peso, Fluência e Esforço. Do ponto de vista do rosto, que é a parte do corpo humano na qual a expressão de emoções mais se concentra, recorro aos achados mais recentes no campo da antropologia e psicologia, principalmente resultante da interação entre duas abordagens: primeiro, a evolucionista (ou inata, ou universal), iniciada no final do século XIX por naturalistas e, depois, a antropológica (ou aprendida, ou cultural), surgida em meados do século XX. Hoje, no diálogo entre estas percepções, recorro à visão de que há um número reduzido de emoções inatas 
(Ekman e Keltner, 1997; Keltner e Ekman, 2008; Ekman, 1999; Ekman, 1972), observável mesmo entre bebês (Burt, 1994; Izard, 1982; Izard e Dougherty, 1980; Izard e Dougherty, 1982): a alegria, a tristeza, a surpresa, a raiva, o medo, o nojo e, mais recentemente, o desprezo (Ekman e Friesen, 1986). Estas 7 emoções básicas, cujos reconhecimentos nas expressões faciais são sinalizados por ações de 43 músculos faciais (Foreman, 2003), podem se tornar complexas por estarem conectadas entre si (por exemplo, uma surpresa seguida de raiva, ou medo) ou se superpor (por exemplo, alegria e tristeza simultâneas). Além disso, especialmente influenciados pela visão culturalista, há estudos sugerindo que as expressões faciais são aprendidas (Birdwhistell, 1952, 1970), bem como as gradações sutis das 7 emoções básicas.

\section{2 - A construção do MaPA (Mapa de Performance Audiovisual)}

O MaPA é constituído por um conjunto de fotogramas selecionados e extraídos de um vídeo de música, aos quais são acrescentados elementos gráficos e indicações textuais sucintas da letra da música (ou sobre a música), movimentos do performer e elementos cênicos da performance.

Um $M a P A$ pode ser constituído por apenas um único fotograma. No vídeo de Atrás da porta (Regina, Buarque, Hime e Oliveira, 1973), gravado em estúdio para posterior exibição em TV, a canção recebeu um arranjo na forma Intro - $A-B 1$ - B2 - Coda. Nele, Elis Regina, que considero um arquétipo da integração textosom-imagem na performance musical, utiliza as pausas no canto como entrelinhas para expressar, por meio de expressões faciais, sentimentos que enriquecem de significado o conteúdo da letra de Chico Buarque. Mostro três MaPAs constituídos de apenas um fotograma cada, em momentos nos quais as expressões faciais da cantora podem ser associadas a sentimentos que fazem parte do universo da personagem da canção: o fim de uma relação amorosa do ponto de vista da mulher submissa, que vai da raiva, passando pela tristeza e à arrogância. Em [1:23] do vídeo (Figura 3), no início da Seção B1, com a coluna ereta, mas com o olhar baixo, aproveitand o a pausa no cantar, logo depois de "...e me arrastei, e te arranhei..." da letra, a cantora projeta e contrai o lábio superior contra o lábio inferior e crispa ambas as mãos ao redor do microfone, sugerindo a emoção básica da raiva (Ekman e Friesen, 2003, Figura 37), refletindo o índice "arranhar" após o índice "arrastar" (a humilhação). 


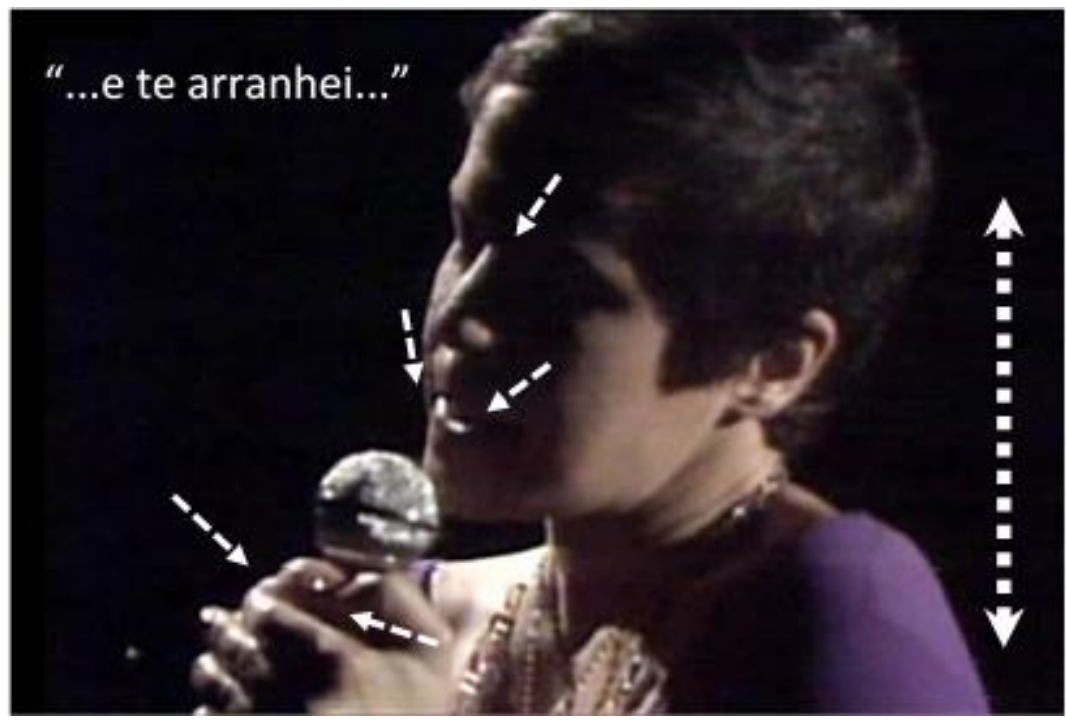

Figura 3: MaPA da expressão de raiva de Elis Regina (Regina, Buarque, Hime e Oliveira, 1973) ao interpretar a letra de Atrás da porta (“...e te arranhei...", em [1:23]) de Chico Buarque: olhar baixo, lábio superior abaixado sobre o lábio inferior tenso, mãos crispadas.

Em [2:24], no início da Seção B2 (Figura 4), com a cabeça se projetando para trás e perdendo a postura mais ereta da coluna, Elis aperta os lábios um contra o outro e afasta as comissuras lateralmente, fecha e aperta os olhos, e franze o cenho no centro da testa. Isto ocorre depois dela cantar “...dei pra maldizer o nosso lar...", o que interpreto como um claro sinal da emoção básica tristeza (Ekman e Friesen, 2003, Figuras 51, 52 e 60) e, também, de culpa, pois, na impotência, diz a letra, ela agrediu algo que tinha de mais sagrado: seu "lar".

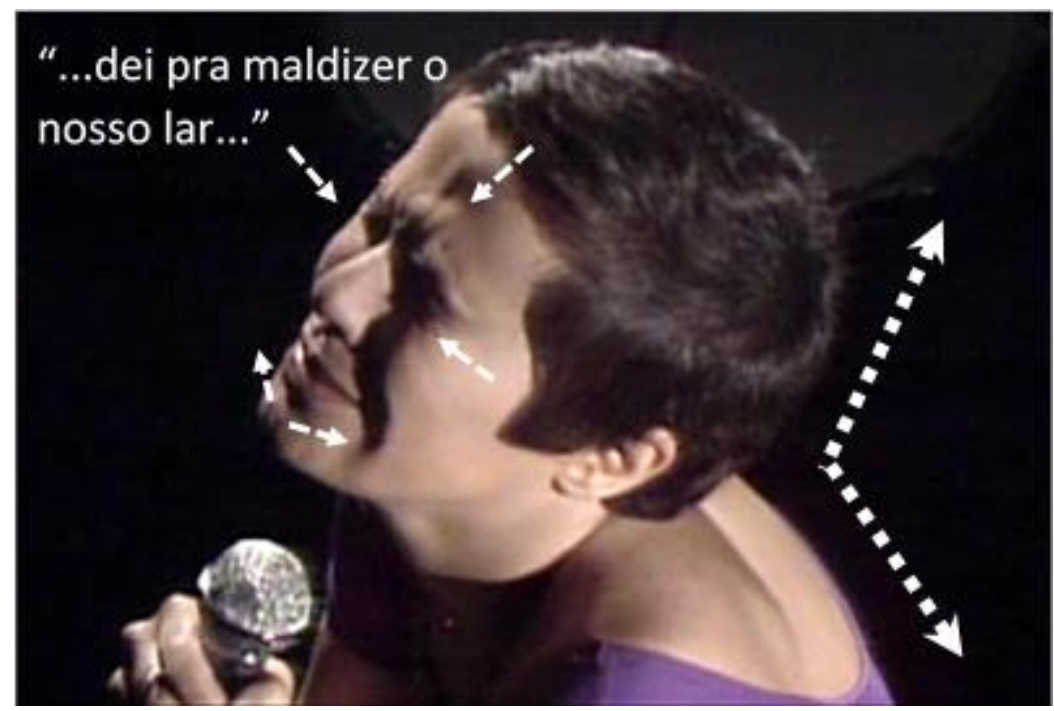

Figura 4: MaPA da expressão de tristeza de Elis Regina ao responder à letra de Atrás da porta (“...dei pra maldizer o nosso lar...", em [2:24]) de Chico Buarque: cenho franzido no centro da testa, olhos apertados, boca apertada, comissuras afastadas lateralmente, cabeça projetada pra trás e coluna perdendo a postura mais ereta. 
Em [2:30], logo antes do clímax da Seção B2 (Figura 5), com o microfone firmemente seguro na mão direita, com as comissuras da boca levemente abaixadas e olhos fechados, Elis eleva a cabeça, corrigindo a posição da coluna para uma posição mais ereta. Depois, congela seus movimentos, impassível. Esta postura de aparente segurança e controle da situação é valorizada pelo efeito da luz frontal cênica que vem do teto. Em silêncio, sem cantar, Elis permanece nesta posição, o que ocorre entre os trechos cantados “...pra sujar teu nome, te humilhar" e "...e me vingar a qualquer preço...". A expressão facial reflete a poesia e dá sinais claros de desprezo (Figuras 1, 2 e 3 de Ekman e Friesen, 1986, p.161-163), emoção básica que comumente dá origem às emoções compostas (DU, Tao e Martinez; 2014) ou afetos (Russell, 1980), que envolvem uma reação à humilhação pela arrogância (o nariz empinado) e vingança ("...te humilhar...").

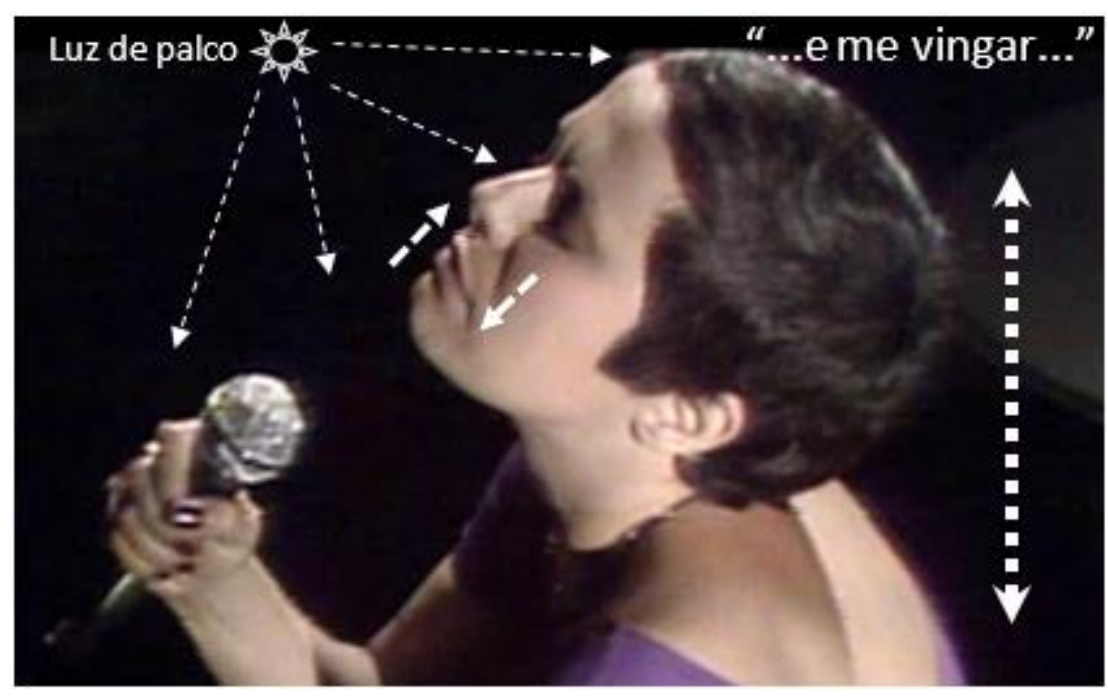

Figura 5: $M a P A$ da expressão de desprezo, arrogância e vingança de Elis Regina ao responder à letra de Atrás da porta (“...e me vingar a qualquer preço...", em [2:30]) de Chico Buarque: comissuras levemente abaixadas, nariz empinado e olhos impassivelmente fechados sob a luz de palco frontal.

Por meio de dois ou mais fotogramas e indicações com setas, um MaPA pode recuperar a ideia de movimentação e expressões faciais das imagens no vídeo (Figura 6). Vejamos o vídeo de Ladeira da preguiça, terceira faixa do DVD Elis Regina: MPB Especial, 1973 (Regina, Gil e Faro, 1973), canção com letra e música de Gilberto Gil, disponibilizado em:

www.youtube.com/watch?v=gNXz5flgWhQ (entre [2:00] e [2:49]).

Na Coda, Elis Regina sugere a malemolência da letra “...esta é a Ladeira da Preguiça...", que Gil lembra ser "...do tempo em que se amarrava cachorro com linguiça". A combinação dos dois fotogramas selecionados sugere a preguiça na rotação do pescoço, a tranquilidade e relaxamento nos olhos cerrados e a expressão de felicidade no sorriso da boca. 

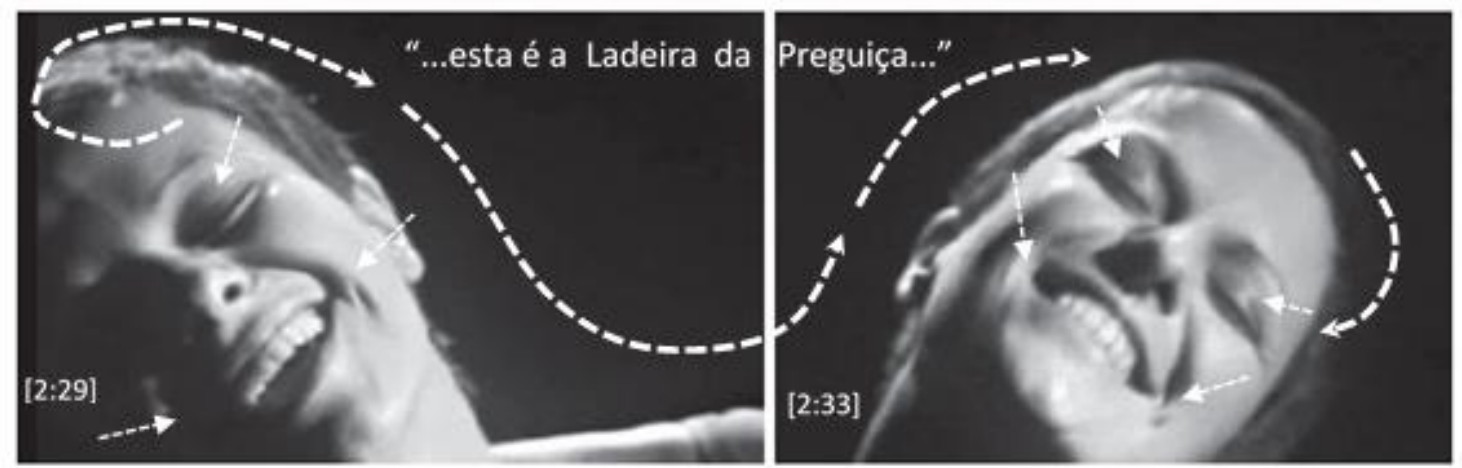

Figura 6: Um MaPA com dois fotogramas com indicações de timing, expressões faciais e movimento de cabeça de Elis Regina na Coda no vídeo Ladeira da preguiça.

Como no vídeo de Elis em Atrás da porta, a naturalidade dos gestos de Elis Regina no vídeo de Ladeira da preguiça aparentemente sugere se tratar de uma gravação no qual o Diretor Fernando Faro registrou uma performance espontânea. Entretanto, eram notórios, em Elis, o perfeccionismo, a predileção por ensaios exaustivos e a atenção a cada detalhe cênico na interpretação, práticas "herdadas" na sua aprendizagem do rigor broadwayniano de Lennie Dale na preparação de shows (Borém e Taglianetti, 2014a, p.42-43). Esses traços e, principalmente, uma comparação entre gravações diferentes da mesma música por ela ao longo dos anos, fundamentam a hipótese de um grande planejamento na integração entre texto, música e imagens. Isto se confirma na automatização e repetição de detalhes de movimentos corporais (tronco, membros, cabeça e expressões faciais), interação com objetos de cena, cenário e iluminação (Borém e Taglianetti, 2014b, p.60-61). Mas como esta performance de Elis inclui também elementos improvisatórios e não completamente controlados, a denomino performance quase-espontânea (uma categoria intermediária do continuum em cujos extremos estão o que chamo de performance espontânea e performance não-espontânea, como exemplificarei mais à frente.

A essência do todo de uma performance musical pode ser sumariada por um MaPA simplificado, constituído por poucas imagens selecionadas ao longo de um vídeo, de modo a representar seu conteúdo e as principais etapas do processo expressivo. A canção Me deixas louca (do compositor mexicano Armando Manzanero, com letra versionada para o português por Paulo Coelho), no arranjo cantado por Elis Regina, segue a forma Intro - $A-A^{\prime}-B-$ Interlúdio 1 - $B^{\prime}$ - Interlúdio 2 - Coda (Perotti e Borém, 2016, p.24). Corporalmente, Elis Regina realiza este arranjo de acord o com um processo amoroso-sexual entre dois amantes: ela e um parceiro imaginário. Este processo pode ser simplificado em quatro fases: sedução pelo olhar, carícias, orgasmo e relaxamento, respectivamente. Este processo descrece uma curva em arco que pode ser imaginada nos quadrantes do Modelo Circumplexo dos Afetos de Russell (p.1980, p.1174). Os afetos positivos no Eixo X (como a sedução, o amor e o sexo 
neste contexto) interagem com os valores negativos que crescem e depois decrescem no Eixo Y (a serenidade seguida de excitação e, depois, de relaxamento). As duas fases mediais deste processo (carícias e orgasmo) se repetem na forma, o que não deixa de ser uma alusão ao símbolo "orgasmo múltiplo feminino". Assim, é possível pinçar quatro fotogramas (Figura 7) de quatro partes formais do arranjo - Intro (sedução), Seção A (carícias), Interlúdio 1 (orgasmo) e Coda (relaxamento), que nos permitem apreciar como Elis Regina constrói sua performance neste vídeo (Regina, Manzanero, Coelho e Oliveira, 2006). A Figura 7a mostra o momento de rotação de cabeça com mudança de direção no olhar sedutor da cantora em direção ao telespectador, com sugestivas contrações dos olhos semi-cerrados e dos lábios apertados um contra o outro. A Figura $7 \mathrm{~b}$ ressalta a posição da cantora com as mãos encolhidas junto ao peito, $\mathrm{o}$ ombro esquerdo levantado e movimento de cabeça, sugerindo respostas às carícias do parceiro imaginário que estaria lhe abraçando. O fotograma da Figura 7c foi selecionado com muita precisão para sugerir os movimentos enérgicos e "involuntários" das mãos e cabeça logo antes do orgasmo. Finalmente, a Figura $7 d$ mostra um fotograma retirado da cena final do videoclipe e ilustra o relaxamento após o orgasmo, com um enquadramento focado no braço da cantora estendido para o alto. A mão já não tem o tônus apropriado para segurar o microfone, o qual que aponta em direção oposta à boca, que já não canta mais.
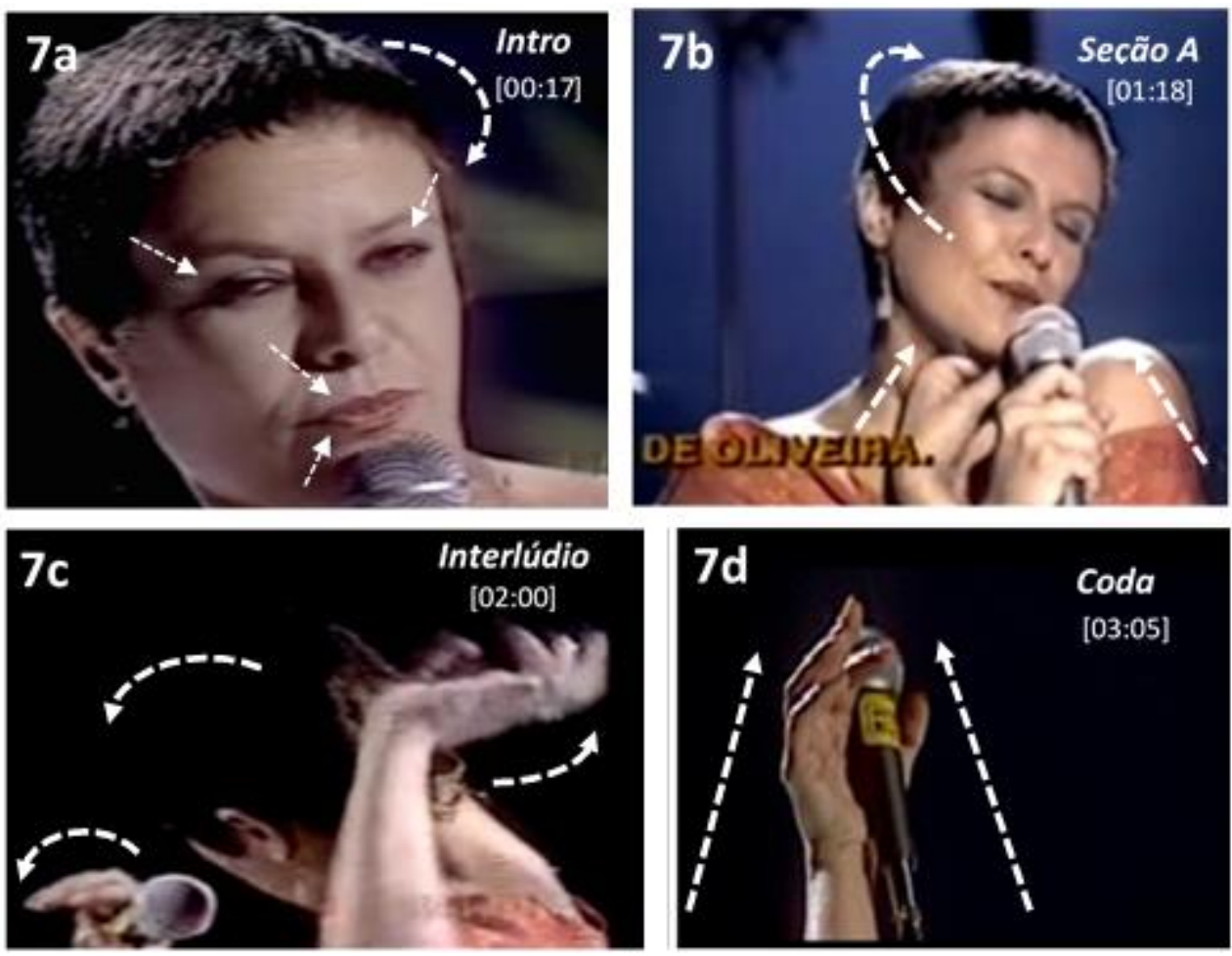

Figura $7 \mathrm{a} / 7 \mathbf{b} / 7 \mathrm{c} / 7 \mathrm{~d}$ : Um $\mathrm{MaP} A$ com 4 fotogramas sumariando a realização corporal de Elis Regina na canção Me deixas louca (Regina, Manzanero, Coelho e Oliveira, 2006), baseada na relação amorosa-sexual: 1- sedução, 2- carícias, 3- orgasmo e 4- relaxamento. 
Se os três MaPAs constituídos por um único fotograma cada (Figuras 3, 4 e 5 acima), revelam elementos de interpretação pontuais de Elis Regina em Atrás da Porta, um MaPA reunindo estes e vários outros fotogramas desta performance permite revelar dados analíticos em um nível mais geral e apontar uma grande coerência e unidade no todo de sua realização. Pode, por exemplo, revelar o processo da complexa transição entre os diversos sentimentos (disparados por palavras da letra caracterizando os Contornos de Ativação). Ou, ainda, permite mostrar a relação entre interpretação e forma musical (como os eventos descritos na letra da música e expressos principalmente no rosto, com a função de preparar o clímax de angústia da Seção B1 e o clímax de angústia da Seção B2). Finalmente, se organizarmos este conjunto sequencial de fotogramas para representar os Segmentos da interpretação, com seus principais Contornos de Ativação, Pontos de Sincronização, elementos de sua Dinâmica e de sua Cinemática, podemos construir um MaPA que revela, ao mesmo tempo, o processo de construção da performance baseada nas expressões faciais e nas relações entre a expressão e a forma. Assim, a Figura 8 ilustra um $M a P A$ bastante completo da performance de Elis Regina no vídeo de Atrás da Porta, cujo arranjo segue a forma Intro - A-B1 B2 - Coda.

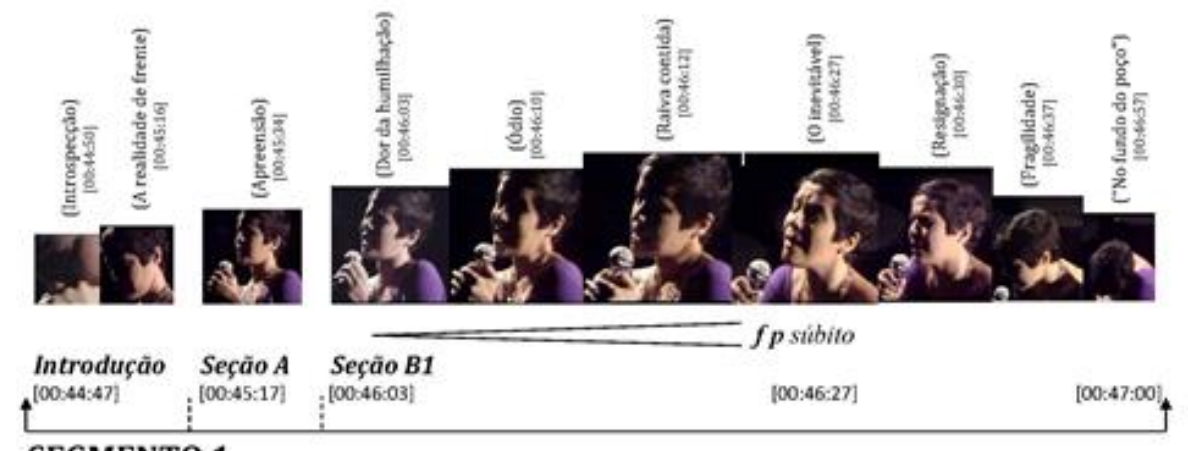

SEGMENTO 1

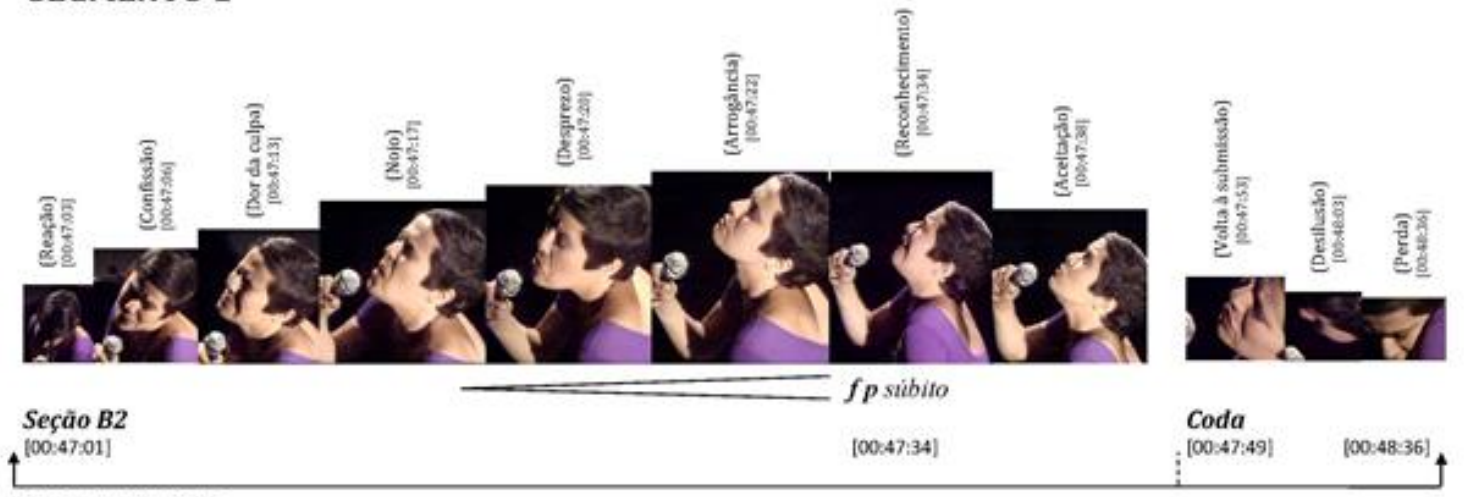

SEGMENTO 2

Figura 8 - MaPA da performance de Elis Regina em Atrás da porta (Regina, Buarque, Hime e Oliveira, 1973) com 21 fotogramas explicitando duas sequências de expressões

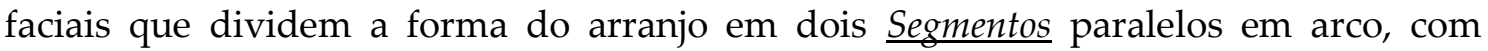
Contornos de Ativação semelhantes, Pontos de Sincronização idênticos, Cinemáticas semelhantes e Dinâmicas semelhantes. 
O MaPA desta realização de Elis contém dois Segmentos paralelos com Contornos de Ativação semelhantes. Pode-se observar a cabeça ocupando cenicamente os planos baixo, alto e baixo (Laban, 1978, p.63-64, 73), respectivamente, ao longo da forma. Há também Pontos de Sincronização idênticos (rosto baixo na penumbra, rosto alto na luz cênica frontal e piano subito após clímax com a cabeça para o alto), Cinemática (movimentos de boca e expressões faciais) e Dinâmicas (intensidade das expressões faciais e clímax com crescendo seguido de forte-piano subito) semelhantes e crescentes.

A frase "Os ouvidos mais afinados juram que Elis nunca repetia uma mesma interpretação, deixando sua voz privilegiada solta para improvisações" (Albin, 2003, p.324) expressa bem o mito e a confusão ao redor da espontaneidade das performances de Elis Regina. De fato, todos os fotogramas dos exemplos acima foram retirados de vídeos de música nos quais identifico uma performance quase-espontânea, ou seja, há um planejamento e controle cênico-musical anterior, tanto nos ensaios (por parte do performer) quanto na gravação do vídeo (por parte do diretor da filmagem e do performer). Há a escolha dos melhores takes, das melhores tomadas pelos camara men em função dos ângulos, da luz etc. Mas há também um certo grau de liberdade na performance, típico da realização musical ao vivo e perceptível na fluência da realização rítmica, na inclusão de efeitos vocais ou instrumentais e nas pequenas assincronias e "erros" que caracterizam a performance como humana. Dos dois lados da performance quase-espontânea, situo a performance espontânea e a performance nãoespontânea, as quais ilustro a seguir com dois MaPAs: um de Elis Regina e outro de Caetano Veloso, respectivamente.

A performance espontânea, em geral, não é espontânea durante toda a sua duração, pois pode incluir um planejamento de ambos performer e diretor do vídeo antes de sua realização. Entretanto, contém trechos da realização musical ou cênica que escapam ao controle do artista, revelando "erros" ou eventos não planejados que, via de regra, são incorporados à performance. Também como via de regra, revelam conteúdos bastante significativos para o contexto daquela realização musical. Recorro mais uma vez a Elis Regina, novamente na canção Atrás da porta, mas em uma gravação de uma performance ao vivo, sem edição de imagens. Ao longo dos anos, Elis Regina manteve, nas suas performances desta canção, a mesma coreografia para seus movimentos básicos de cabeça. Desde a primeira gravação importante desta canção, em preto e branco, sob a direção de Fernando Faro, passando pela gravação dirigida por Roberto de Oliveira (analisada acima) até a última, dirigida por Daniel Filho, suas performances de Atrás da porta são baseadas em dois arcos emocionais consecutivos (descritos acima), delineados pelo sobe-desce-sobe-desce da cabeça (que valoriza a iluminação cênica na sequência escuro-claro-escuro-claro-escuro) que, por sua vez, enfatiza a forma e a construção dos dois clímax gerados pela 
linha melódica de Francis Hime e letra de Chico Buarque (veja Figura 8 acima). Sete anos depois da gravação dirigida por Roberto de Oliveira, Elis repetiu seu plano geral de performance na gravação realizada por Daniel Filho (Borém e Taglianetti, 2014b, p.66), que foi incluída na série Grande Nomes da Rede Globo (Regina, Buarque, Hime e Filho, 1980) e exibida pouco mais de um ano antes de seu trágico falecimento (Ferreira, 2005). ${ }^{9}$ Elis repete com extrema precisão um Ponto de Sincronização crucial de sua performance na gravação feita sete anos antes. Em [1:32], no decrescendo logo após o clímax da Seção B1, ela realiza a mesma e delicada convenção rítmica sobre a palavra "pé" na frase "...Nos teus pés, ao pé da cama...". Sincronizadamente com toda a banda, Elis cai na nota Fá\#2, após um glissando descendente de oitava, vindo de uma nota longa, o Fá\#3 (Regina, 2014, p.72, c.31). Até aqui, nada de espontâneo.

Mas há diversos indícios imagéticos e auditivos neste vídeo de que o habitual controle de performance característico de Elis se rendeu à espontaneidade das emoções que estava vivendo, ${ }^{10}$ como mostra um MaPA desta performance (Figura 9). Na cena inicial, o zoom sobre a pequena figura de Elis sentada sobre uma banqueta alta realça a fragilidade psicológica da cantora na fase final de sua vida. Ali, sentada, Elis permanece 22 segundos (de [0:12] a [0:34]) sem mostrar seu rosto para o público; inquieta, ela balança os pés (em [0:16]) como se buscasse conforto para iniciar a canção. Durante 29 segundos (de [0:46] a [1:15]), Elis canta escondendo o rosto com a mão esquerda, claramente tomada por uma emoção que não consegue controlar nos gestos e na voz. No início do canto, em [0:24], a nota Lá na sílaba "lhas" em "Quando o-lhas-te bem..." sai desafinada, baixa, quase um Lá bemol. Devido a iminência do choro, seu canto quase não pode ser ouvido. Em [0:49], percebe-se várias falhas voz em "...e me arrastei...". Em seguida, ao pronunciar “...e duvidei..." em [0:59], a sílaba "dei” é

\footnotetext{
9 Este vídeo de Atrás da porta foi exibido em 3 de outubro de 1980 na Rede Globo, no programa "Elis Regina Carvalho Costa". Elis faleceu em 19 de janeiro de 1982.

${ }^{10} \mathrm{O}$ próprio ex-marido de Elis Regina, César Camargo Mariano, relata outra experiência de choro de Elis em um ensaio de Atrás da porta (Pinheiro, 2015): “O primeiro show que fiz com a Elis, em 1971, no Teatro da Praia, no Rio de Janeiro, tinha a direção do Ronaldo Bôscoli, que já havia se separado [de Elis]... No meio de um dos ensaios cismei com um acorde, chamei o Hélio [Delmiro, guitarrista] e disse: "...Nessa hora a Elis costuma segurar mais a nota e a gente precisa encontrar uma solução para ela poder cantar dessa forma". A conversa durou a tarde toda e o Ronaldo [Bôscoli], impaciente, andando para lá e para cá, veio se queixar: "César, para com isso! Que obsessão é essa?! Vocês estão a tarde inteira nesse acorde...[...] Disse a ele: '...o cara que está lá no fundo, quando ouvir esse acorde perfeito, ele nem saberá disso, mas é esse acorde que vai provocar nele um arrepio no coração. Esse acorde, do jeito que eu e Helinho estamos pensando, vai fazer com que Elis sinta-se confortável na interpretação e essa emoção vai atingir o público... acertamos tudo e chamei a Elis para passar a música. Quando chegou na hora do acorde, que é bem no trecho 'Dei pra mal dizer o nosso lar...', ela entoou a frase, os olhos dela se encheram de lágrimas e ela não parou de chorar."
} 
emitida com muito esforço e com o timbre muito entubado. Fisiologicamente, a dificuldade de Elis em articular as palavras e manter o fluxo da coluna de ar constante em diversos momentos desta gravação ao vivo, se relaciona com o aumento do fluxo de sangue e oxigênio no trato vocal, gerados pelo estresse da tristeza. Por isso, há uma expansão involuntária da glote, para deixar passar mais ar. O engolir seco (típico do processo do choro) ou a articulação de consoantes (que demanda mais a contração das cordas vocais) atuam com força contrária à expansão da glote, gerando uma tensão, que é sentida como um "nó" (ou "bolo") na garganta (Shere, 2013) e que causa os problemas técnicos observados nesta análise. Continuando, ao cantar “...e te arranhei..." em [1:11], Elis já não expressa a mesma raiva no rosto e no canto das gravações anteriores, mas uma grande fragilidade na voz, entrecortada, com uma expressão facial de derrota. Em [1:42], na articulação da palavra "tapete", a vogal central " $\mathrm{e}$ " é repetida fragmentadamente, semelhante ao efeito do tremolo dos instrumentos de arco. Este problema técnico de emissão da voz continua em “...no tapete atrás da porta... reclamei...", até que fica muito evidente na palavra "baixinho", como se ela gaguejasse. A banqueta, que funciona como objeto de cena para as canções mais lentas e intimistas do show, se transforma em uma muleta em [2:54], na qual Elis apoia seu corpo abatido, cansado da performance que parece ser muito exaustiva. Em [3:14], Elis põe a língua para fora rapidamente, como que buscando saliva para molhar os lábios, provavelmente com a sensação de boca seca. $\mathrm{Na}$ Coda, em [2:57], com o trato vocal já todo tomado pela emoção, o planejado uníssono em boca chiusa com a linha melódica do piano não funciona e Elis é obrigada a cantar de boca aberta e, mesmo assim, se torna quase inaudível. Finalmente, já com o aconchego das palmas do público, ela marca o final da performance apertando os olhos energicamente, deixando escorrer lágrimas de um choro real em [3:24]. Este é outro sinal da espontaneidade da performance de Elis. Entre as 16 emoções ligadas a alterações secretomotoras do sistema nervoso autônomo listadas por Levenson (2014, p.109), a tristeza é a única ligada à produção de lágrimas. 


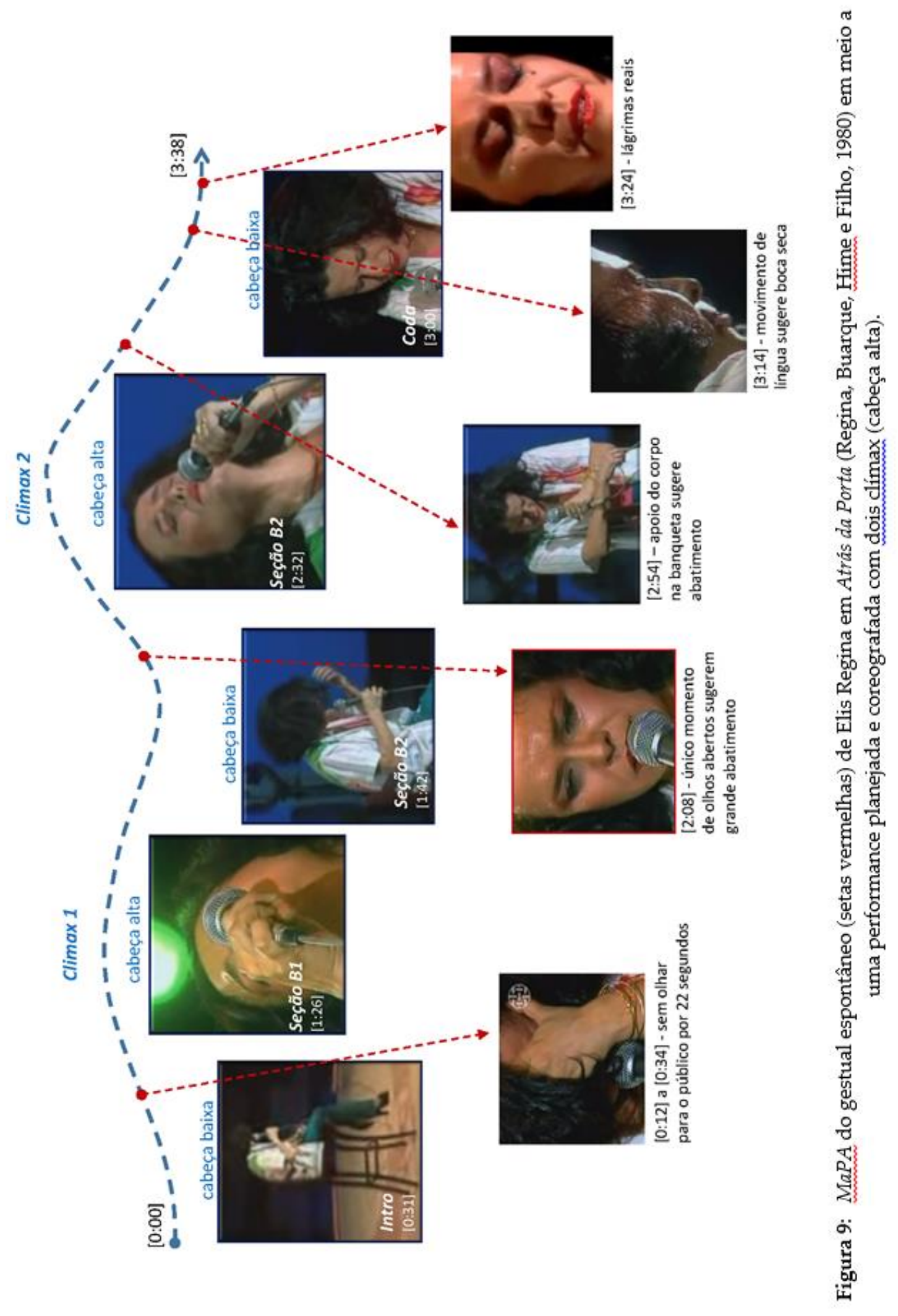


Mas o descontrole do choro de tristeza também se manifesta em outros níveis; ${ }^{11}$ o que explica o fato de, durante os quase 4 minutos de duração do vídeo, Elis evitar o contato visual com o público. Ela abre seus olhos apenas uma vez e brevemente (apenas 3 segundos, entre [2:08] e [2:11]), e só os reabre de novo quando já não canta mais, após o fim da canção, em [3:26]. Se compreendermos as dificuldades de Elis nesta performance, dentro do conceito de Esforço de Laban (1978, p.57, 73, 76, 79, 86 e 126), podemos descrevê-la como centrada na cabeça e tronco, dentro de um Espaço confinado de sua cinesfera (Laban, 1978, p.69), se desenrolando dentro de um Tempo sustentado, fraca e tensa quanto ao Peso e com uma Fluência aos trancos. Mas, talvez por isso, tenha se tornado uma de suas performances mais emocionantes, um “...instante iluminado...momentos antológicos da televisão brasileira" (Ferreira, 2005).

A performance não-espontânea incorpora e enfatiza estéticas imagéticas experimentais ou consolidadas das linguagens cinematográficas e dos videoclipes. Por isso, não pretende transmitir a naturalidade da performance musical ao vivo. Requer uma interferência maior do diretor artístico (ou diretor de imagens) e, geralmente, demanda um trabalho criativo de manipulação das imagens gravadas, deixando aparente seu trabalho de "composição" superposto à interpretação musical. A gravação da música não é ao vivo (geralmente, o diretor da filmagem aproveita uma faixa de áudio de CD, MP3 etc.), que além de ser ouvida pelo espectador, é utilizada pelo artista como playback para coreografar seu gestual e/ou sincronizá-lo com o áudio (no caso das canções, a chamada sincronia labial ou lip sync). A performance não-espontânea envolve muitos takes da mesma cena, tomadas de vários ângulos com várias câmaras, efeitos especiais, cortes e um grande trabalho de montagem. $\mathrm{O}$ apelo visual dos videoclipes se tornou tão forte na música comercial que o lançamento de um novo CD (ou formatos mais recentes de áudio de música) vem quase sempre acompanhado de uma versão multimidiática de uma faixa escolhida, chamada de "música de trabalho". Estes videoclipes de música popular (mas também, em menor grau, de música erudita) envolvem produções caras, patrocinadas por grandes empresas, como a Vevo, para serem massivamente divulgadas e se tornarem a faixa carro-chefe daquele lançamento.

Desta maneira, o videoclipe da canção A Bossa Nova é foda de Caetano Veloso, dirigido pelos video makers Fernando Young e Tonho Quinta-feira (Veloso, Young e Quinta-feira, 2013) em:

www.youtube.com/watch?v=orPhkLpX3ps)

${ }^{11}$ Rottenberg et al (2002, p.302) descrevem: “Chorar é uma resposta secretomotora definida pela liberação de lágrimas das estruturas lacrimais. O choro de tristeza geralmente vem acompanhado de franzimento do cenho e outras expressões faciais de tristeza, vocalizações e a inspiração e expiração convulsiva da coluna de ar." 
foi gravado e montado com cenas realizadas em estúdio, sem instrumentos musicais. Some-se a isto a característica do compositor-cantor-intelectual de se esmerar na utilização de gírias, figuras de linguagem, charadas, trocadilhos, mensagens subliminares e contextos históricos e socioculturais, que serviram de pretexto para os diretores criarem relações além dos significados óbvios e imediatos (Borém, 2016). Neste tipo de vídeo de música, não se pretende a espontaneidade. Por exemplo, pode-se apreciar por 11 segundos (de [0:14] a [0:25]), o cantor de boca fechada, apesar de se ouvir sua voz no trecho "... quem terá tido esta fazenda [...] uns restos de rabada...". O alto grau de interferência dos diretores na edição de imagens resulta em uma Segmentação do vídeo que delineia claramente as seções da forma musical, gera um grande número de Pontos de Sincronização entre imagens e sons, e estabelece Contornos de Ativação com Cinemáticas e Dinâmicas muito bem demarcadas.

O resultado é uma profusão de imagens escolhidas e editadas que reiteram e interagem com a sofisticação e codificações da letra, interações que são planejadas e fabricadas para ilustrar, dialogar, contrapor ou, mesmo, subverter os sentidos do áudio. No título e na letra da canção, está contida a intenção de Caetano de desafiar um símbolo nacional consolidado, ao propor "...um retrato da Bossa Nova como gesto histórico e estético agressivo, e não o clichê da coisa doce e suave [...]" (Veloso, 2012, [1:27-1:43]). Por isto, um MaPA que pretenda representar o rico universo deste vídeo precisa conter muitos fotogramas (Figura 8). A edição de imagens em movimento permite ao diretor atuar de maneira semelhante a um compositor de música, que escolhe motivos, os desenvolve, os contrasta entre si e os faz recorrer ao longo da forma. Outra motivação para a ênfase visual desta performance não-espontânea foi inspirada no próprio planejamento do arranjo, que justapõe gêneros musicais (blues, rock, bossa e valsa), de maneira muito bem demarcada (instrumentação, levadas, métricas e relação texto-música), que não se misturam ou hibridizam, mas caracterizam a fricção de musicalidades proposta por Piedade (2003). No MaPA de A Bossa Nova é foda, o motivo do rosto do cantor imobilizado por mãos marca o início das seções formais em que predominam o blues (levada e instrumentação). As imagens mais agressivas (a mão amordaçando a boca do cantor, o gesto obsceno com o dedo médio, os golpes da luta MMA, ou Mixed Martial Arts, as poses desafiadoras e o fogo) são reservadas ao refrão da canção, o qual está associado ao rock. As alusões espiritualistas (um ícone do hinduísmo sugerido pelo deus com vários braços, coreografado por Caetano e seus músicos em [1:09]; um índice do transe do candomblé, sugerido na dança e olhos virados de Caetano em [1:25]) são superpostas à suavidade do gênero bossa e à letra que homenageia Tom Jobim e Vinícius de Morais. Outro gênero suave, a valsa, mesmo que não tenha letra, pois trata-se de um interlúdio instrumental, recebe um tratamento imagético 
semelhante (a água; a aura humana; a fé católica, sugerida pelo ícone de um escapulário no peito de Caetano, revelado entre os braços dos músicos em [2:47]).

$\mathrm{O} M a P A$ permite visualizar relações analíticas tanto pontuais quanto mais gerais. A utilização de cores no $M a P A$, agora mais aceita na veiculação de artigos científicos na forma virtual (o que solucionou os custos da impressão colorida em papel), facilita e otimiza a representação e leitura desses elementos analíticos (Figura 10). Por exemplo, imagens selecionadas do vídeo podem refletir o contraste e a provocação entre os estereótipos masculinos e femininos, que foram a motivação criativa de Caetano por trás de A Bossa Nova é foda. Abaixo da montagem de fotogramas deste $M a P A$, pode-se apreciar os Segmentos masculinos (representados pelo gênero blues, em azul escuro, e pelo rock, em roxo) e os Segmentos femininos (o gênero bossa, em azul claro, e o gênero valsa, em rosa), suas seções formais internas (Intro, $A 1, A 2, A 3, A 4, B, C$, Refrão e Coda) com seus respectivos timings e suas associações com os gêneros musicais. Os timings anotados em negrito vermelho, de valores crescentes $\left(8^{\prime \prime}, 16^{\prime \prime}, 38^{\prime \prime}\right.$ e $\left.45^{\prime \prime}\right)$, mostram a predominância gradual do gênero rock, o que explicita, temporalmente, a intenção do título da canção. ${ }^{12}$ É possível apreciar, ao longo dos Segmentos deste MaPA, uma dialética de materiais musicais opostos (blues/rock versus bossa/valsa) e muito bem separados entre si (daí sua não-hibridação). Ao final, chegamos a uma "mediação" desta polarização, por meio de uma coexistência hierarquizada (com predomínio do masculino) sem perda de identidade (do feminino), que ocorre no Segmento $I^{\prime \prime}$. Ao mesmo tempo, é possível visualizar, em níveis locais, índices que mostram o feminino como força desafiadora, como o índice da imagem do fio d'água se movendo verticalmente contra a gravidade (de [3:25] a [4:08]) na Coda.

A utilização de fotogramas contendo links direcionados para arquivos de vídeo e de áudio (uma característica que está sendo implementada mundialmente em publicações científicas, como na base SciELO do Brasil) é outra possibilidade de ilustrar a apresentação dos dados analíticos. Isto permite ao leitor acompanhar auditivamente e visualmente (com imagens em movimento) a análise apresentada em trechos de pequena, média e larga escala.

12 Caetano utiliza o significado mais recente da gíria "foda" entre os três apresentados em O Dicionário do Aurélio online (Buarque de Holanda, 2015), ou seja, significando "o melhor", especialmente nos meios masculinos dos esportes radicais, como o MMA (Mixed Martial Arts). 


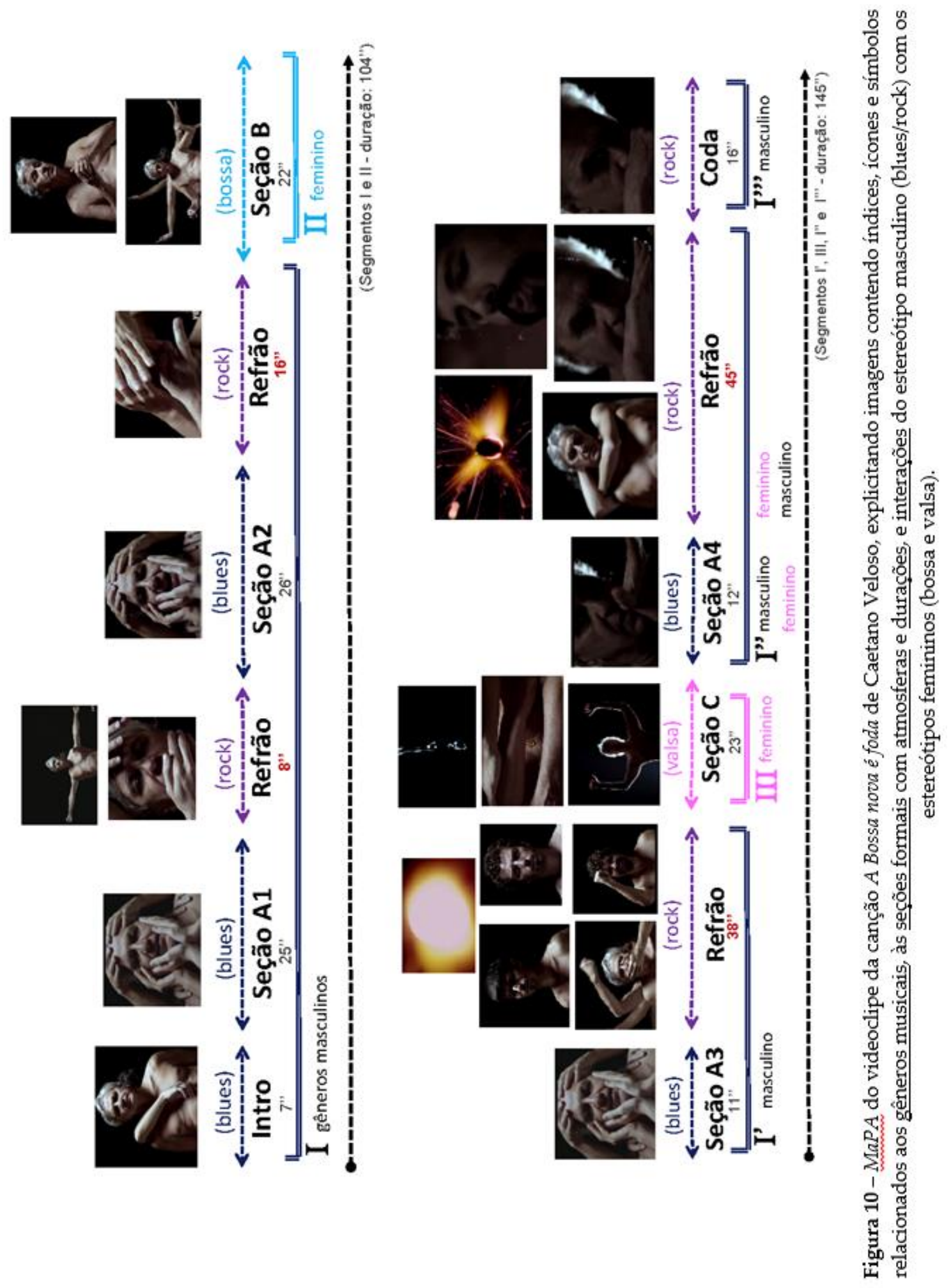




\section{3 - A contrução da EdiPA (Edição de Performance Audiovisual)}

A EdiPA é uma partitura sobre a qual são colocados fotogramas do MaPA, informações textuais concisas e sinais gráficos indicando elementos de análise relevantes para facilitar a compreensão da performance apresentada em um vídeo de música. A Figura $2 \mathrm{a} / 2 \mathrm{~b}$ no início do artigo é uma EdiPA simples, e contém um elemento básico em sua construção: a transcrição musical a partir de informações audiovisuais que não são encontradas ou documentadas na literatura tradicional sobre música (como os livros e as partituras). Partituras tradicionais também podem ser utilizadas para se elaborar uma EdiPA, com anotações de práticas de performance que podem revelar dados técnicos ou estilísticos de uma composição ou interpretação. A Figura 11 mostra uma EdiPA (Ribeiro, Borém e Rocha, 2015; Ribeiro e Borém, 2015; Ribeiro e Borém, 2012) de um trecho baseado na partitura do Andante do Concerto Op.3 do contrabaixistacompositor-maestro Serge Koussevitzky (1985, p.5), acompanhada de um espectrograma de sua gravação histórica (Koussevitzky e Luboshutz, 1929). Nesta EdiPA estão indicadas três práticas de performance: rubato, portamento e vibrato, elementos essenciais para se compreender os estilos de interpretação cambiantes na música erudita na primeira metade do século $X X$. A régua em décimos de segundos mostra com precisão os timings dos eventos musicais, as variações de andamento da realização rítmica (que se reflete visualmente nas distâncias entre as notas musicais), os três tipos de portamento (inicial, conclusivo e com nota intermediária) e as gradações do vibrato (amplitude, taxa e continuidade). A régua também permite medir, para fins comparativos, as durações exatas de cada compasso na performance gravada (indicadas em vermelho, abaixo da pauta, nos c.4 e c.8). Outros dados poderiam ser extraídos do espectrograma, como as intensidades, articulações e aspectos dos timbres, expressos na variação de intensidade e de cores das parciais evidenciadas na série harmônica. 


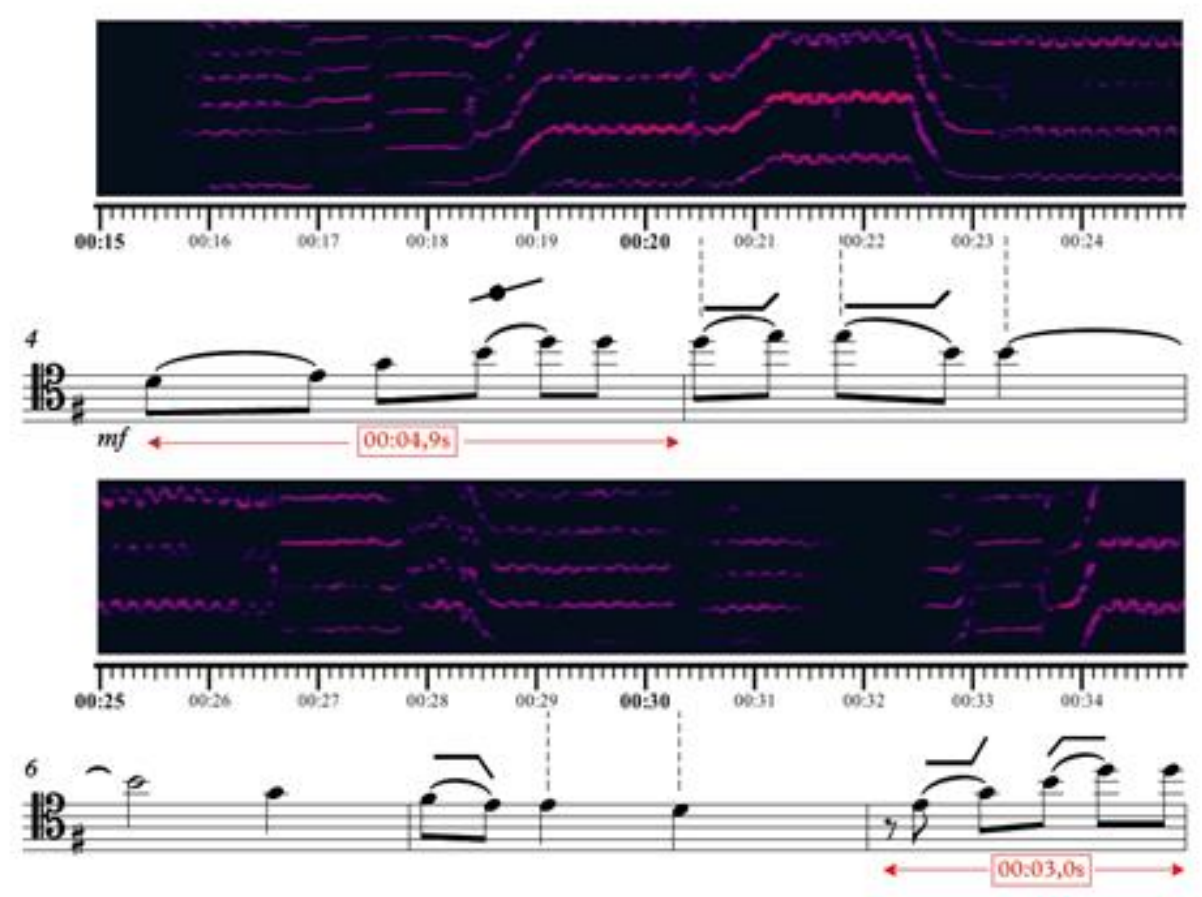

Figura 11: Uma EdiPA da gravação histórica de 1929 do Concerto Op.3 do compositorcontrabaixista Serge Koussevitzky, com indicações de timings de eventos, rubati, portamenti e vibrati (Ribeiro, Borém e Rocha, 2015).

Uma EdiPA também pode ser construída a partir da transcrição de uma gravação de áudio apenas pois, ao final, poderá trazer elementos analíticos audiovisuais que auxiliam na compreensão da composição e sua performance. A Figura 12 mostra uma EdiPA de trecho da música Cannon, para flauta solo com técnicas estendidas e sons eletroacústicos, composta e interpretada por Hermeto Pascoal (1977). No espectrograma desta música (Borém e Freire, 2010, p.70; Pascoal, 2010, p.81, c.31-33), pode-se avaliar a técnica de humming e humming nasal, realizadas simultaneamente com o assoprar tradicional da flauta, cujo resultado é a condução de um contraponto com duas vozes contrárias e, depois, a realização de um uníssono (parte inferior e media da pauta). A parte superior da pauta mostra um terceiro estrato, referente às linhas de sons gravados e manipulados que foram superpostas às vozes da flauta e huming. 


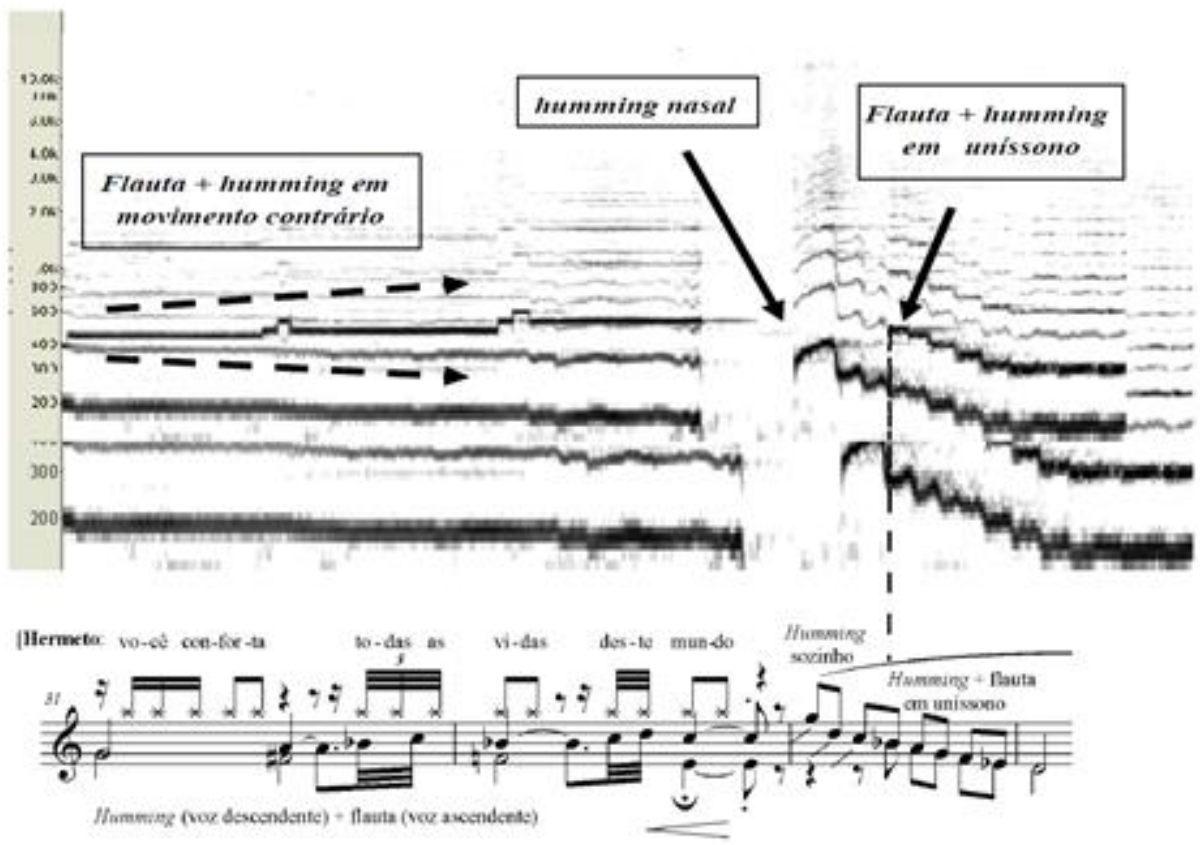

Figura 12: Uma EdiPA (partitura transcrita emparelhada com espectrograma) de trecho da música Cannon para flauta e sons pré-gravados, composta e interpretada por Hermeto Pascoal.
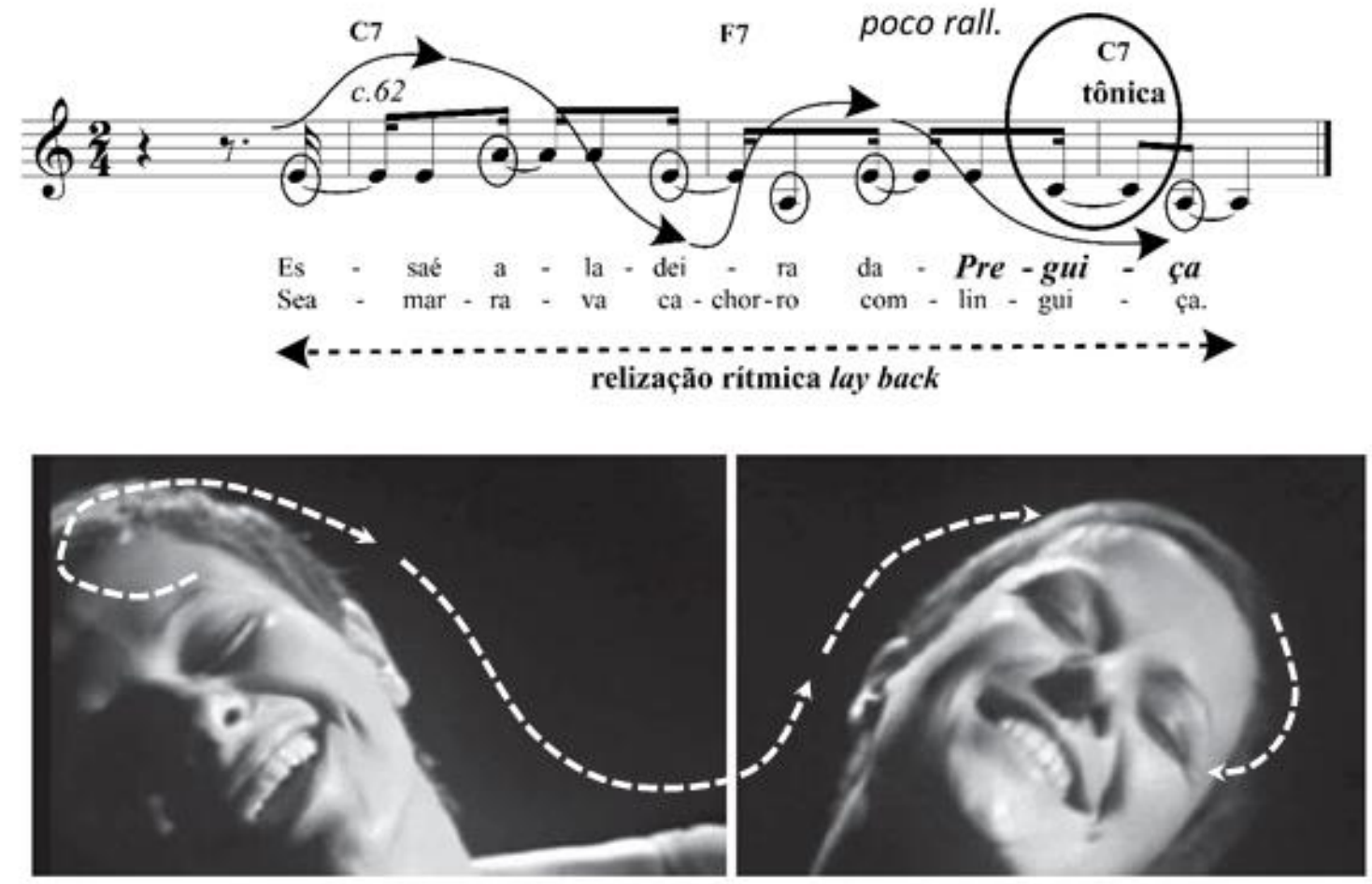

Figura 13: Uma EdiPA da Coda de Ladeira da preguiça mostrando a ênfase audiovisual de índices contidos na letra e melodia de Gilberto Gil e incorporados no gestual de Elis Regina. 
As relações do trinômio texto-som-imagem podem ser melhor apreciadas na realização musical se, visualmente, emparelharmos fotogramas do vídeo de música com a partitura. A EdiPA na Figura 13 foi elaborada a partir do MaPA da Figura 6 (mostrada anteriormente) e revela que a sinuosidade do movimento de cabeça de Elis Regina e sua realização atrasada (lay back) na Coda de Ladeira da preguiça, intuitivamente ou não, reflete a sinuosidade da linha melódica (no caso, transcrita em uma lead sheet) e da letra de Gilberto Gil, procedimento que gera uma grande ênfase audiovisual.

Na música popular, a notação musical geralmente é muito simplificada e esconde práticas de performance relevantes para a análise musical. Na interação entre gêneros musicais mostrada anteriormente na Figura 8, Caetano recorre a três efeitos vocais - yodel, ${ }^{13}$ fry $^{14}$ e falsete ${ }^{15}$ - para sublinhar atmosferas sugeridas pelo blues, rock e bossa na sua canção A Bossa Nova é foda (veja a Figura 8, mostrada anteriormente). Para explicitar o impacto destes gêneros na relação texto-som-imagem, as três EdiPAs da Figura 14a/14b/14c trazem: (1) fotogramas selecionados do vídeo; (2) a transcrição musical de trechos musicais com melodia e cifras; (3) os efeitos vocais com suas localizações, tanto na partitura quanto no timing no vídeo; (4) os trechos da letra que motivaram os efeitos vocais; e (5) a codificação de cores para os gêneros nas indicações dos trechos (azul escuro/blues, roxo/rock e azul claro/bossa). Na Figura 14a, a natureza rural do blues (e da country music norte-americana, por extensão) é lembrada na letra (“...fazenda de areais...") e no yodelling da voz que homenageia Bob Dylan, “...o bardo judeu romântico de Minnesota...", cuja admiração Caetano expressa com um semi-sorriso e um leve movimento lateral de pescoço. Na Figura 14b, a natureza agressiva do rock aparece na gíria masculina "é foda" da letra, cantada

${ }^{13} \mathrm{O}$ yodel (ou iodelei) é um estilo de canto onomatopaico típico de zonas rurais em diversos países, caracterizado pela rápida e audível troca de registro entre a voz de cabeça e a voz de peito, ou seja, ou seja, do ponto de vista da fonoaudiologia, entre os mecanismos laríngeos M1/M2 e M3 (KOB et al, 2011, p.362-363). Tornou-se muito popular no Tirol devido à sua geografia acidentada, a qual favorece a reverberação e eco na sua execução. Foi utilizada na música erudita até o final do século XIX, como na canção Il Viaggio a Rheim de Rossini (Wise, 2007, p.1). Hoje, é muito comum na música pop, country, sertaneja, etc.; o ambiente rural a que remete o estilo foi tratado com humor por Rita Lee na canção Tiroleite (Rita Lee, Arnaldo Baptista, Sérgio Dias e Liminha) no disco Hoje é primeiro dia do resto de sua vida (Lee, Polydor, 1972, faixa 7).

${ }^{14} \mathrm{O}$ fry (ou creak ou strohbass ou crepitação ou som basal), é um estilo de canto que se popularizou em gêneros como o pop (na região media e aguda) e rock (como rhythm and blues, heavy metal e punk rock na região grave). É produzido no mecanismo laríngeo M0 (Kob et al, 2011, p.363, 366) e caracterizado pela rápida abertura e fechamento do ciclo respiratório (Cielo 2011, p.365-367).

${ }^{15}$ O falsete (ou sons superagudos; Cielo 2011, p.367, ou voz de cabeça ou registro loft, Wise, 2007) é um estilo de canto produzido no mecanismo laríngeo M2 (Kob et al, 2011, p.363), principalmente por homens para atingir a região do soprano, por meio da vibração das pregas vocais por justaposição incompleta (Gurry, 2014, p.119). 
com o efeito vocal fry na região mais grave do cantor. Neste momento, no vídeo, o cantor tem o rosto imobilizado por mãos, como nas lutas de MMA (esporte radical favorito de João Gilberto, um dos símbolos da Bossa Nova). Na Figura $14 \mathrm{c}$, o súbito movimento de cabeça e rugas na testa de Caetano sugerindo surpresa (Ekman e Friesen, 2003, Figuras 9 e 10), mas também suavidade, sublinham o canto em falsete que fala do "...tom de tudo...", numa referência a Tom Jobim e sua paixão pelas "...ondas do mar..." (como na letra de sua música Wave). A pauta desta transcrição ainda revela a inovação de um estilo harmônico mais sofisticado na Bossa Nova (o acorde maior com sétima maior, A7M) e a prática jobiniana de repetir a mesma nota na linha melódica, acompanhada por uma progressão harmônica cromática.
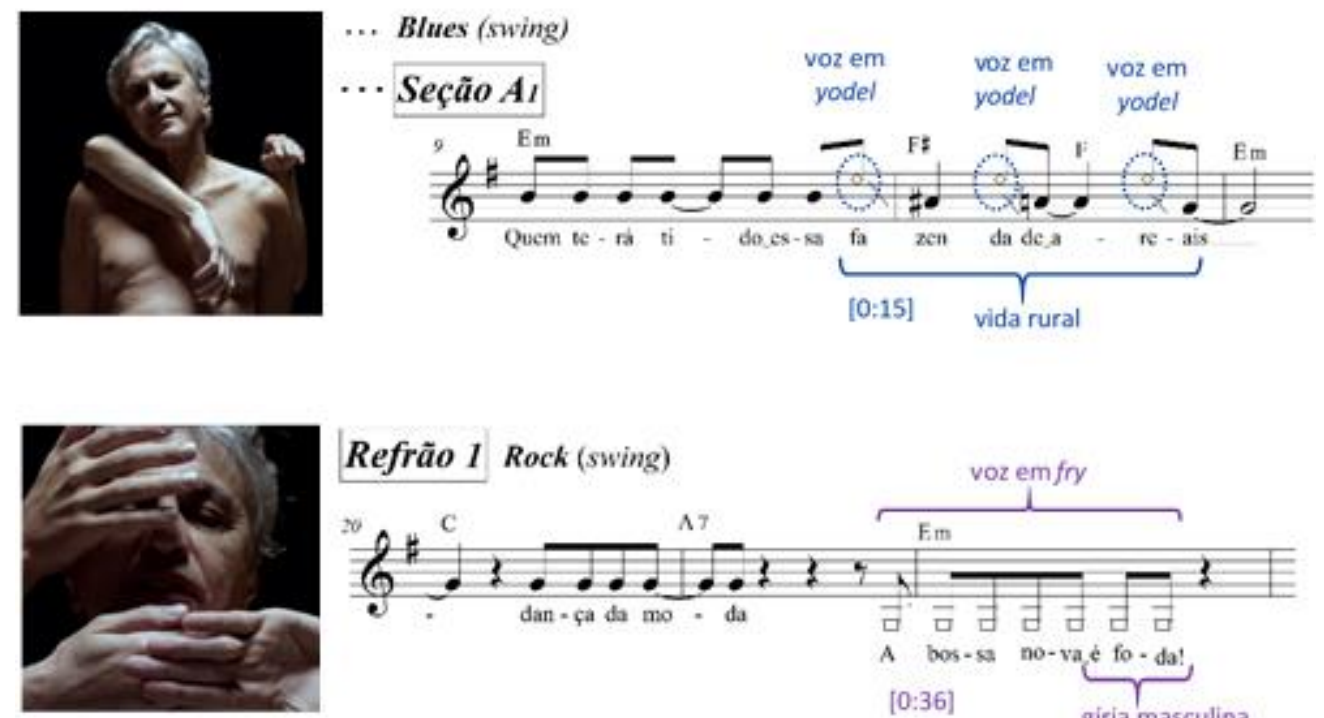

Refrão 1 Rock (swing)
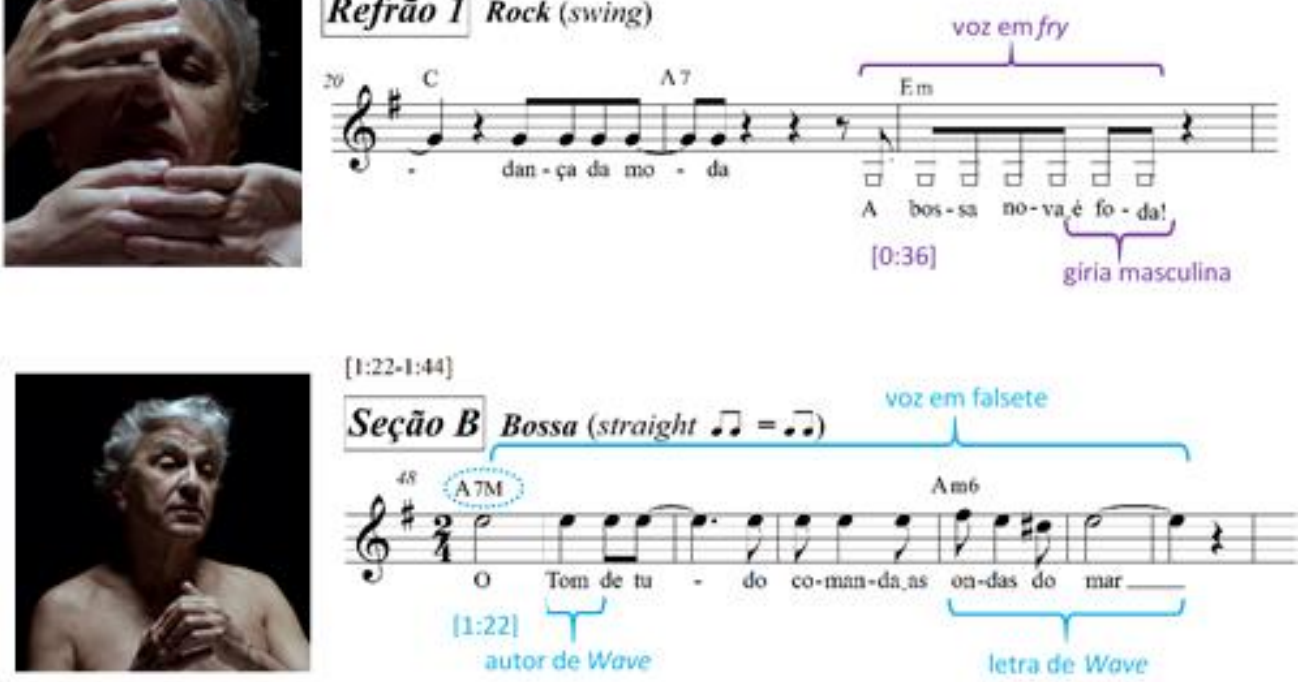

Figura 14a/14b/14c: Três EdiPAs dos efeitos vocais de Caetano Veloso associados a gêneros musicais (blues, rock e bossa), letra e imagens no vídeo A Bossa Nova é foda.

Finalmente, apresento uma EdiPA de uma música completa. Além de apresentar dados do processo de análise e síntese, ela provê uma partitura para a realização musical contendo características estilísticas do compositor, do letrista, do performer e do diretor do vídeo. Desta forma, a Figura 15 traz a primeira página da partitura da canção Atrás da porta, resultante de uma criação 
artística a dez mãos: a intérprete Elis Regina, o letrista Chico Buarque, o compositor Francis Hime, o editor de songbooks Almir Chediak e o diretor de imagem do vídeo, Roberto de Oliveira (Regina, Buarque, Hime, Chediak e Oliveira, 2014). Se, por um lado, esta partitura permite uma leitura analítica da obra, por outro, dá ao intérprete um documento a partir do qual pode emular, diversificar ou contrariar uma interpretação anterior.

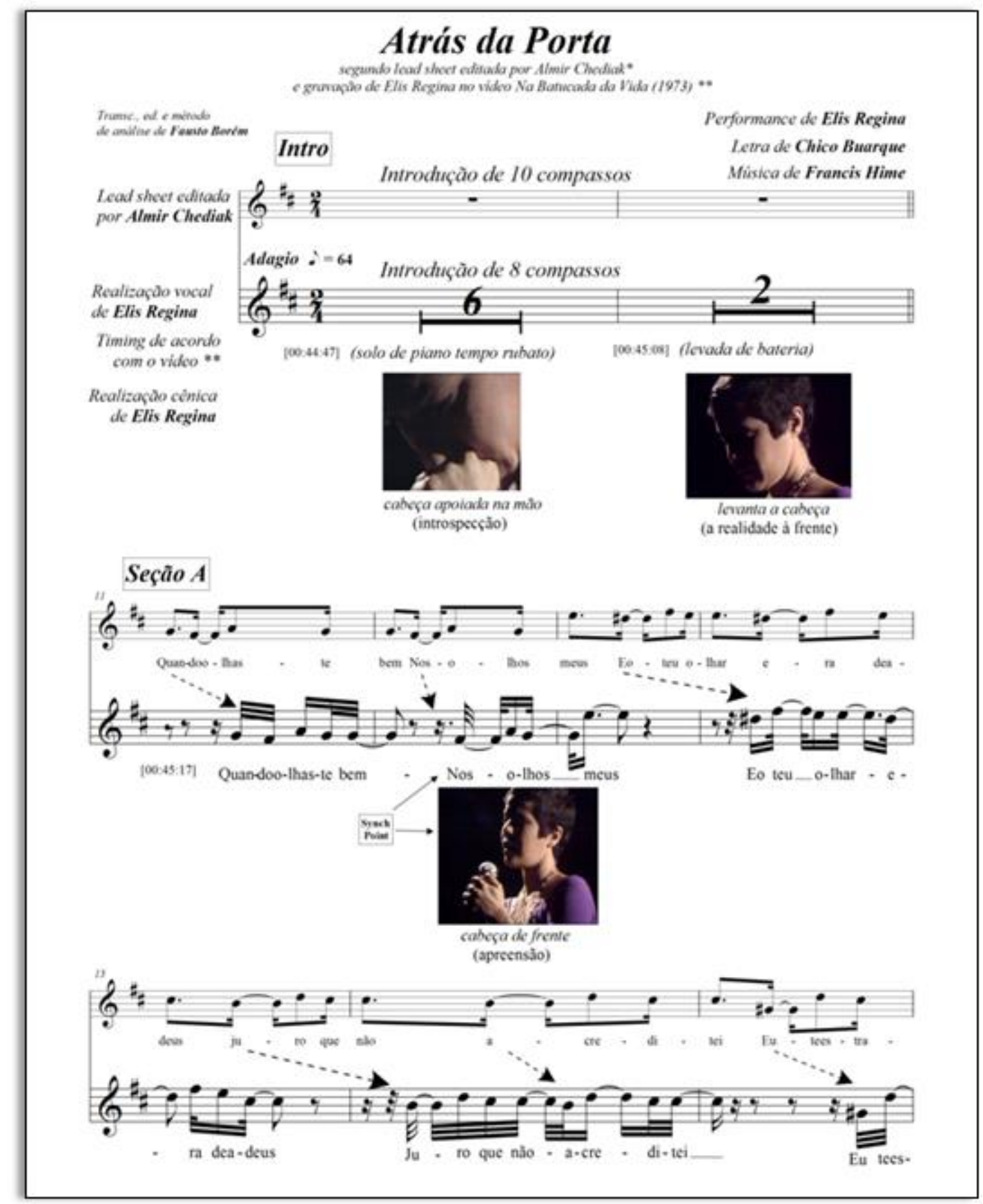

Figura 15: Página de uma EdiPA completa da canção Atrás da porta de Chico Buarque e Francis Hime, transcrita por Almir Chediak, interpretada por Elis Regina e dirigida por Roberto de Oliveira (Regina, Buarque, Hime, Chediak e Oliveira, 2014), contendo duas realizações, fotogramas e indicações de dados analíticos. 


\section{4 - Considerações finais}

A grande carência de ferramentas metodológicas para a análise de vídeos de música (Cook, 1998, p.v) me motivou no desenvolvimento do MaPA (Mapa de Performance Audiovisual) e da EdiP A (Edição de Performance Audiovisual), propostos e explicados no presente artigo. Com eles, busco caminhos que facilitem a compreensão de uma variedade de fontes primárias com grande potencial de representação e expressividade no trinômio texto-som-imagem (gravações em vídeo de concertos, shows, óperas, balés, filmes, documentários, entrevistas, reportagens, comerciais e videoclipes). Nestas fontes, a explicitação das relações entre expressões faciais e gestos corporais maiores, objetos de cena, cenário e iluminação (que geralmente compõe o ambiente da realização musical) permitem compreender aspectos estilísticos não apenas dos intérpretes, mas também dos compositores, letristas/poetas/libretistas (no caso da música cantada) e diretores de imagem dos vídeos. Ambos o MaPA e a EdiPA, que podem ser tratados como ferramentas consecutivas (uma EdiPA é mais facilmente construída a partir de seus $M a P A s$ ), são flexíveis para abrigar diversas abordagens e linguagens analíticas.

O conteúdo e a maneira de construção do $M a P A$ podem estar ligados ao tipo de controle exercido sobre a performance pelo intérprete ou pelo diretor de cena. Na maioria das gravações de shows, em estúdio ou ao vivo, observo que predomina a performance quase-espontânea (como na maioria das gravações de Elis Regina; exemplificado nas Figuras 3, 4, 5, 6, 7 e 8). Neste tipo, observa-se, ao mesmo tempo, grande liberdade na realização cênico-musical, mas também um cuidadoso planejamento e controle tanto sonoro quanto coreográfico. Já em um dos extremos do continuum que contém as performances quase-espontâneas situo as performances não-espontâneas (como exemplificado no videoclipe de Caetano Veloso; Figura 10), na qual a interpretação cênico-musical sofre grande controle, tanto por parte dos artistas quanto, principalmente, por parte do diretor de imagem, que atua como um co-compositor da interpretação. Na maioria dos videoclipes de hoje, predominam as performances não-espontâneas. Neles, a gravação das imagens é posterior à gravação do áudio, o que exige um trabalho de sincronização dos movimentos do corpo (principalmente da boca) com o que se ouve no playback. Na outra extremidade deste continuum de naturalidade das imagens situo a performance espontânea (como exemplificado em trechos de uma gravação de show ao vivo de Elis Regina; Figura 9), cujo conteúdo (ou parte dele, como é mais comum) escapa ao controle dos músicos ou do diretor de imagem. Assim, são registrados não apenas erros e improvisações, mas também momentos com emoções profundas e espontâneas.

Um MaPA pode ser construído com um único fotograma (Figuras 3, 4, e 5), para representar eventos e relações pontuais, em níveis mais locais da música, 
como os detalhes das expressões faciais e Pontos de Sincronização. MaPAs com alguns fotogramas (Figura 6) permitem observar eventos cujas relações ocorrem em níveis um pouco mais gerais, como as indicações de movimentos, articulações de Segmentos e mudanças de Cinemática ou Dinâmica das imagens. Já os MaPAs com mais fotogramas (Figuras 7, 8, 9 e 10) geralmente conseguem abarcar eventos e suas relações em níveis mais globais, sumariando o todo do vídeo, como as relações formais de larga escala e mudanças de atmosfera ou humor com seus Contornos de Ativação.

Os escopos de construção das EdiPAs geralmente seguem as mesmas amplitudes dos MaPAs em que foram baseados, podendo se resumir, por exemplo, a um único ou dois fotogramas emparelhados com um pequeno excerto de partitura. Este tipo pode ser útil em exemplos musicais sobre práticas de performance pontuais não documentadas no papel (Figura 2 e Figura 14) e para indicação de Pontos de Sincronização entre texto, música e movimento (Figura 13). EdiPAs com vários excertos musicais ou excertos musicais mais longos permitem comparar Contornos de Ativação, Cinemáticas e Dinâmicas de diferentes Segmentos. EdiPAs de músicas completas (Figura 15) podem ser úteis a leitores interessados tanto na compreensão dos dados de análise e síntese dos processos composicionais e interpretativos, quanto aos instrumentistas, cantores e maestros interessados na realização da música, corroborando, diversificando ou contrariando traços estilísticos daquela performance. Finalmente, EdiPAs podem ser elaboradas emparelhando partituras com respectivas imagens de espectrogramas retirados de arquivos de áudios (Figuras 11 e 12), as quais podem relevar, com precisão, dados de andamento, articulação, intensidade, timbre e timings de eventos.

\section{Referências}

\section{Referências de texto}

1. Albin, Ricardo Cravo. 2003. O Livro de ouro da MPB: a história de nossa música popular de sua origem até hoje. Rio de Janeiro: Ediouro.

2. Auslander, Philip. 2005. Sound and vision: Record of the past or performance in the present? In: CHARM Symposium 1: Comparative perspectives in the study of recordings (Royal Holloway, University of London, 14 a 16 April 2005); http://charm.cchcdn.net/redist/pdf/s1Auslander.pdf.

3. Birdwhistell, Ray L. 1952. Introduction to Kinesics: An Annotation System for Analysis of Body Motion and Gesture. Louisville: University of Louisville Press. 
4. - 1970. Kinesics and Context: Essays on Body Motion Communication. Philadelphia: The University of Pennsylvania Press.

5. Borém, Fausto. 2016. “...Foda!”: a bossa das palavras, música e imagens de Caetano Veloso. ARJ-Arts Review Journal n.3. Natal: ANPPOM/ ABRACE/ ANPAP.

6. 2014. Por uma análise da performance em vídeos de música, um "Mapa Visual de Performance" (MVP) e uma "Edição de Performance Audiovisual" (EPA). In: Anais do $1^{\underline{o}}$ Congresso da TeMA. Org. por Marcos da Silva Sampaio. Salvador: UFBA. p.100-108.

7. Borém, Fausto; Freire, Maurício. 2010. Cannon de Hermeto Pascoal: aspectos musicais e religiosos em uma obra-prima para flauta. Per Musi. n.22. Belo Horizonte: UFMG. p.63-79.

8. Borém, Fausto; Taglianetti, Ana Paula. 2014a. A trajetória cênico-musical de Elis Regina. Per Musi. n.29. Belo Horizonte: UFMG. p.39-52.

9. 2014b. Texto-música-imagem de Elis

Regina: uma análise de Ladeira da Preguiça, de Gilberto Gil e Atrás da porta, de Chico Buarque e Francis Hime. Per Musi. n. 29. Belo Horizonte: UFMG. p. 53-69.

10. Burt, John W. 1994. Body, face and voice: nonverbal, expression of emotion in infancy. Filadélfia: Haheman University (Tese de Ph.D em Psicologia Clínica e Terapia com Artes Criativas).

11. Cielo, Carla A. et al. 2011. Músculo tireoaritenoidiano e som basal: uma revisão de literatura. Revista Brasileira de Fonoaudiologia. v.16, n.3. p. 362-369.

12. Clayton, Martin. 2007. Analysing video recordings of musical performances. In: CHARM Symposium 4: Methods for analysing recordings. Eghan: Royal Holloway, University of London, 12 a 14 de abril, 2007.

http://www.charm.rhul.ac.uk/about/symposia/p7_10_1.html

13. Cook, Nicholas. (no prelo) "Song into video into film: 'Bohemian Rhapsody', 'Wayne's World' and beyond". In: The Cambridge Companion to Film Music, Editado por Peter Franklin e Robynn Stilwell (Cambridge: Cambridge University Press, forthcoming). 
14. 2013. Beyond the score: music as performance. Oxford: Oxford University Press.

15. 1998. Analyzing musical multimedia. Oxford: Oxford University Press.

16. Cook, Nicholas; Chan, Carol (Org.). 2007. Anais do CHARM RMA Annual Conference: Musicology and Recordings. Egham, Inglaterra: CHARM/Royal Holloway, University of London.

17. Ekman, Paul. 1972. Universals and cultural differences in facial expressions of emotion. In: Nebraska Symposium on Motivation, ed. por J. K. Cole, v.19. Lincoln: University of Nebraska Press.

18. Du, Shichuan; Tao, Yong; Martinez, Aleix M. 2014 (março). Compound facial expressions of emotion. Proceedings of the National Academy of Sciences of the United States of America - PNSA. In: www.pnas.org/content/111/15/E1454.

19. 1999. Facial expressions. In: Handbook of cognition and emotion. Org. por T. Dalgleish e M. Power. Capítulo 16. Nova Iorque: John Wiley \& Sons. p. 301-320.

20. Ekman, Paul; Friesen, Wallace V. 1986. A New pan-cultural facial expression of emotion. Motivation and emotion. v.10, n.2. Plenum Publishing. p. 159-168.

21. Ekman, Paul; Keltner, Dacher. 1997. Universal facial expressions of emotion: an old controversy and new findings. Org. por Ullica Segerstrale e Peter Molnár. In: Nonverbal communication: where nature meets culture. Manwah, New Jersey: Lawrence Erlbaum Associates. p. 27-46.

22. 2003. Unmasking the face: A guide to recognizing emotions from facial expressions. Los Altos, California: Malor Books.

23. Feaster, Patrick. 2010. Édouard-Léon Scott de Martinville: An Annotated Discography ARSC Journal. v.51, n.1. Association for Recorded Sound Collections. p.43-82.

24. Ferreira, Mauro. 2005. Elis Regina Carvalho Costa: DVD com especial da Globo exibido em 1980 flagra cantora em momento iluminado. In: Isto é: Gente. Revista online. Postado em 09 de janeiro de 2005.

http://www.terra.com.br/istoegente/333/diversao_arte/musica_elis_regina.htm. 
25. Foreman, Judy. 2003. A Conversation with Paul Ekman: The 43 Facial Muscles That Reveal Even the Most Fleeting Emotions. New York Times. 5 de Agosto. http://www.nytimes.com/2003/08/05/health/conversation-with-paul-ekman-43facial-muscles-that-reveal-even-most-fleeting.html.

26. Gil, Gilberto. 2003. Gilberto: todas as letras. Org. Carlos Rennó. Textos de Arnaldo Antunes e José Miguel Wisnik. Participação especial de Marcelo Fróes. Ed. revista e ampliada. São Paulo: Companhia das Letras.

27. Gomery, Douglas. 1985. The Coming of sound. In: Film sound. Org. Elizabeth Weis e John Belton. New York: Columbia University Press. p. 6-24.

28. Goodwin, Andrew. 1992. Dancing in the distraction factory: music television and popular culture. Minneapolis: University of Minnesota Press.

29. Gurry, Néstor Ramón Cordero. 2014. A Voz de tenor: bases históricas da pedagogia vocal a partir do Bel Canto até os conceitos metodológicos da atualidade. Belo Horizonte: UFMG (Dissertação de Mestrado).

30. Haga, Egil. 2008. Correspondences between music and body movement. Oslo: University of Oslo, Faculty of Humanities. (Tese de Doutorado).

31. Izard, Caroll E. 1982. Measuring emotions in infants and children. New York: Cambridge University Press.

32. Izard, Caroll E.; Dougherty, L. M. 1980. A System for Identifying Affect Expressions by Holistic Judgments (AFFEX). Newark: Instructional Resources Center/University of Delaware.

33. 1982. Two complementary systems for measuring facial expressions in infants and children. In: Measuring emotions in infants and children. Org. C. E. Izard. New York: Cambridge University Press.

34. Keltner, Dacher; Ekman, Paul. 2008. Facial expression of emotion. In: Handbook of emotions. $2^{\underline{a}}$ ed. Cap.15. Org. Michael Lewis e Jeannette M. HavilandJones. New York: Guildford Publications.

35. Kob, Malte; Heinrich, Nathalie; Herzel, Hanspeter; Howard, David; Tokuda, Isao; Wolfe, Joe. 2011. Analysing and understanding the singing voice: recent progress and open questions. Current Bioinformatics. v.6, n.3. p. 362-374. 
36. Laban, Rudolf. 1978. Domínio do movimento. Org. e ed. Lisa Ullmann. Trad. Anna Maria Barros de Vecchi e Maria Silvia Mourão Netto. Apresentação de Maria Duschenes. São Paulo: Summus Editorial.

37. Levenson, Robert W. 2014. The Autonomic Nervous System and Emotion. Emotion Review. v.6, n.2, April. International Society for Research on Emotion/Sage. p. 100-112.

38. Martinville, Édouard-Léon Scott de. 2008. World's First Audio Recording, 1860 - www.pastfinder.de. In: https://www.youtube.com/watch?v=s0fhEpxrFvo. Áudio de 15 segundos de 1860 publicado no Youtube por Pastfinder em 29 de março, 2008.

39. Merrell, Floyd. 2001. Charles Sanders Peirces's concept of the sign. In: The Routledge Companion to semiotics and linguistics. Org. Paul Cobley. Londres: Routledge. p.28-39.

40. Perotti, Deniele; Borém, Fausto. 2016. Relações texto-música-imagem de Elis Regina em Me deixas louca. Série Diálogos Musicais da Pós: Práticas de Performance. Belo Horizonte: Minas da Música. p. 20-32.

41. Piedade, Acácio Tadeu de Camargo. 2003. Brazilian Jazz and Friction of Musicalities. In: Planet Jazz: Transnational Studies of the "Sound of Surprise". Ed. E. Taylor Atkins. University Press of Mississippi. p. 41-58.

42. Pinheiro, Marcelo. 2015. Elis Regina, segundo Cesar Camargo Mariano: nos 70 anos a cantora, o compositor, arranjador e produtor radicado nos EUA fala sobre a intimidade artística entre ele e a saudosa Pimentinha. In: http://brasileiros.com.br/2015/03/elis-regina-segundo-cesar-camargo-mariano. Terra, Seção Brasileiros. Postado em 17 de março de 2015, atualizado em 2 de maio de 2015 (Acesso em 20 de fevereiro de 2016).

43. Ribeiro, Alfredo; Borém, Fausto; Rocha, Edite. 2015. Variações de timing e escolhas estéticas na gravação histórica do Andante do Concerto Op.3 de Serge Koussevitzky. In: Anais do 25ํㅡㄹ Congresso da ANNPOM. Vitória: ANPPOM

44. Ribeiro, Alfredo; Borém, Fausto. 2015. Concerto Op.3 de Serge Koussevitzky: rubati, vibrati e portamenti em uma gravação histórica de 1929. Série Viva Música. Belo Horizonte: UFMG (Comunicação em Power Point). 
45. 2012. Portamento e vibrato no Andante do Concerto Op.3: práticas de performance do contrabaixista-compositor Serge Koussevitzky. In: Anais do 22ํㅡ Congresso da ANPPOM. João Pessoa. p. 1832-1840.

46. Rottenberg, Jonathan; Gross, James J.; Wilhelm, Frank H.; Najmi, Sadia; Gotlib, Ian H. (2002) Crying Threshold and Intensity in Major Depressive Disorder. Journal of Abnormal Psychology. v.111, n.2. Washington, DC: American Psychological Association. p. 302-312.

47. Shere, Jeremy. 2013. What causes a lump in your throat? In: Moment of Science. http://indianapublicmedia.org/amomentofscience/a-lump-in-your-throat. Postado em 19 de março de 2013 (Acessado em 15 de fevereiro de 2015).

48. Wise, Thimothy. 2007. Yodel species: a typology of falsetto effects in popular music vocal styles. Radical Musicology. v. 2. Ed. Richard Middleton e Ian Biddle. Newcastle: Newcastle University (Centre for Music Studies).

\section{Referências de partitura}

49. Gil, Gilberto. 1992. Ladeira da Preguiça. In: Songbook: Gilberto Gil. Edição de Almir Chediak. v.2, 3ํㅡㄹ ed. Rio de janeiro: Lumiar, p. 96-97.

50. Koussevitzky, Serge. 1985. Concerto Op.3, N.1-3, for string bass and piano. Série Kalmus Classic Edition. New York: Kalmus (Partitura K-04459).

51. Pascoal, Hermeto. 2010. Partitura de Cannon (dedicada a Cannonball Aderley), para flauta, humming na flauta e sons pré-gravados. Per Musi, n.22. Belo Horizonte: UFMG, p.v80-82.

52. Regina, Buarque, Hime, Chediak e Oliveira. 2014. Atrás da porta segundo lead sheet editada por Almir Chediak e gravação de Elis Regina no vídeo Batucada da Vida. Per Musi. n.29. Ed. Fausto Borém. Belo Horizonte: UFMG. p.70-74 (Partitura de música).

\section{Referências de vídeo}

53. Dickson, William. 2013. The First American Movies (1891- 1895) - Thomas Edison - W. Dickson - Kinetoscope, Kinetophone. In:

www.youtube.com/watch?v=vfqUjBDIkT8 (vídeo de 1 minuto e 1 segundo de 1894-1895 publicado no Youtube por "Cinema History" em 7 de janeiro de 2013, acesso em 20 de janeiro de 2016). 
54. Miéle, Luis Carlos. 2009. Lennie Dale - Trecho do documentário Dzi Croquettes 2010.mpg. In: www.youtube.com/watch?v=kbOWiPeLAvw (Vídeo de 12 minutos e 9 segundos, retirado documentário da Tria Produções e Canal Brasil de 2009, dirigido por Tatiana Issa e Raphael Álvarez e disponibilizado no Youtube em 3 de dezembro de 2010 por "eduardolott1"; acesso em 02 de fevereiro de 2016).

55. Regina, Elis; Gil, Gilberto; Faro, Fernando. 1973. Elis Regina - "Ladeira da Preguiça" - Ensaio - MPB Especial. In: www.youtube.com/watch?v=gNXz5flgWhQ (vídeo de 02 minutos e 52 segundos, retirado do DVD Elis Regina: MPB Especial, 1973 e DVD Trama AA 100000, disponibilizado no Youtube por "Trama TV" em 15 de outubro de 2007; acesso em 2 de fevereiro, 2016). Direção de Fernando Faro. Com Elis Regina (canto, entrevistas); César Camargo Mariano (piano); Hélio Delmiro (guitarra); Luizão Maia (contrabaixo); Paulinho Braga (bateria), entre outros.

56. Regina, Elis; Buarque, Chico; Hime, Francis; Oliveira, Roberto de. 1973. Elis Regina: Atrás da porta, 1973. In: www.youtube.com/watch?v=SJ2JatcXQx0 (vídeo de 03 minutos e 49 segundos, retirado do trecho do DVD Na batucada da vida de 2006, e postado no Youtube por Jordão Qualquer em 27 de setembro de 2008; acesso em 7 de fevereiro de 2016). Direção de Roberto de Oliveira. Com Elis Regina (canto); César Camargo Mariano (piano); Hélio Delmiro (guitarra); Luizão Maia (contrabaixo); Paulinho Braga (bateria).

57. Regina, Elis; Buarque, Chico; Hime, Francis; Filho, Daniel. 1980. Elis Regina: Atrás da porta ao vivo. In: www.youtube.com/watch?v=35FPZR24djg (vídeo de 03 minutos e 38 segundos, retirado da série Grandes Nomes TV Globo e postado no Youtube por "ninne" em 18 de abril de 2006, acesso em 7 de fevereiro de 2016). Com Elis Regina (canto); César Camargo Mariano (arranjos e regência), Daniel Filho (Direção de imagem, assistência de Maurício Nunes e João Paulo Carvalho).

58. Regina, Elis; Manzanero, Armando; Coelho, Paulo; Oliveira, Roberto de. 2006. Elis Regina: Me deixas louca. In:

https://www.youtube.com/watch?v=t08AusBApQA (vídeo de 03 minutos e 05 segundos, retirado do DVD Falso Brilhante da Universal Music e postado no Youtube por "Maria Elisa Horn Iwaya" em 18 de junho de 2006, acesso em 7 de fevereiro de 2016). Direção de Roberto de Oliveira. Com Elis Regina (canto); participação especial de César Camargo Mariano (piano e arranjos).

59. Veloso, Caetano. 201). Caetano diz que 'bossa nova é mais foda que o tropicalismo'. In: TV Folha. Vídeo de 3 minutos e 43 segundos minutos, publicado em 2 de dezembro, 2012 por TV Folha.

https://www.youtube.com/watch?v=P8J4y5AZhMA. 
60. Veloso, Caetano; Young, Fernando; Quinta-feira, Tonho. 2013. A Bossa nova é Foda. Com Caetano Veloso (música, canto, atuação), Pedro Sá (guitarra, canto, atuação), Ricardo Dias Gomes (baixo, piano elétricos, canto, atuação), Marcelo Callado (bateria, canto, atuação), Fernando Young e Tonho Quinta-Feira (direção de vídeo). Vídeo com duração de 4 minutos e 16 segundos. Disponibilizado no Youtube em https://www.youtube.com/watch?v=orPhkLpX3ps. Publicado por Universal Music Brasil em 15 de abril de 2013.

\section{Referências de áudio}

61. Koussevitzky, Serge; Luboshutz, Pierre. 1929. Koussevitzky Plays Koussevitzky (Concerto Op. 3, II. Andante). In: www.youtube.com/watch?v=1fTexStjP_A. Áudio de 6 minutos e 33 segundos, postado no Youtube por "baroquecello" em 20 de janeiro de 2001. (Acessado em 12 de janeiro de 2016). Com Serge Koussevitzky (contrabaixo) e Pierre Luboshutz (piano). Gravado em 25 de setembro de 1929; primeiro lançamento pela RCA Victor 99-2000.

62. Lee, Rita; Baptista, Arnaldo; Dias, Sérgio; Liminha. 1972. Tiroleite. In: Hoje é primeiro dia do resto de sua vida. Com Rita Lee e Mutantes. Polydor, faixa 2 do lado B (LP 2451.017).

63. Pascoal, Hermeto. 1977. Cannon. In:

www.youtube.com/watch?v=7wkCNhTC-0U Slaves Mass. Áudio de 5 minutos e 24 segundos, postado no Youtube por “jeromeknvb" em 4 de outubro de 2010. Com Hermeto pascoal (flauta e voz) com participações vocais de Flora Purim, Airto Moreira, Hugo Fattoruso, Raul de Souza e Laudir de Oliveira. Lançado pela WEA/Warner (LP BS2980). 